\title{
The Gleaner
}

Vol 21 (1997)

In Memoriam of Leandros Vranousis

\section{O EPANI $\Sigma T H \Sigma$}

EKAOEH TOY «OMIAOY MEAETHE TOY EAAHNIKOY AIAФQTIIMOY,

$\operatorname{ETO} \Sigma \Lambda \Delta^{\prime}-\Lambda \mathrm{E}^{\prime}$

T O MO 21

MNHMH $\Lambda$ EAN $\triangle$ POY BPANOY $\Sigma H$

A OHNA

1997

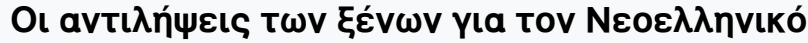

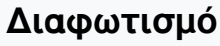

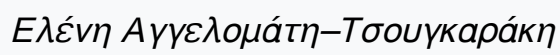

doi: $10.12681 / \mathrm{er} .214$

To cite this article:

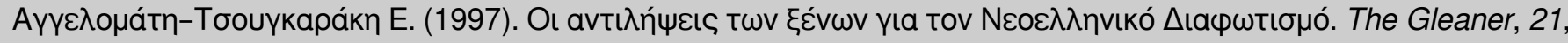
225-247. https://doi.org/10.12681/er.214 


\section{OI ANTI $\Lambda$ H $\Psi E I \Sigma T \Omega N ~ \Xi E N \Omega N$ $\Gamma I A T O N$ NEOE $\Lambda \Lambda H N I K O \Delta I A \Phi \Omega T I \Sigma M O$}

$\mathrm{H}$

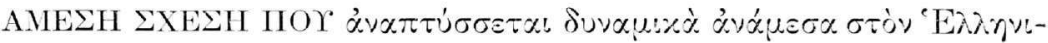

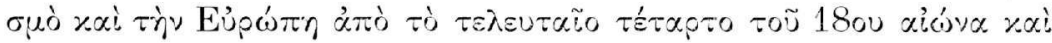

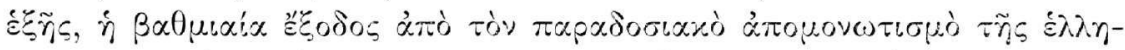

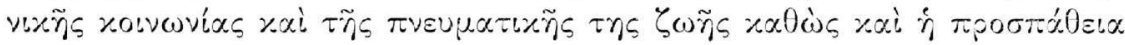

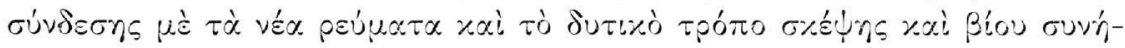

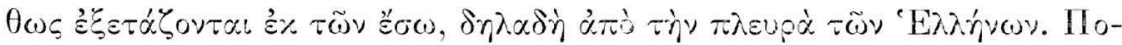

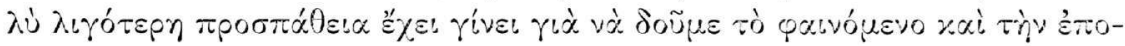

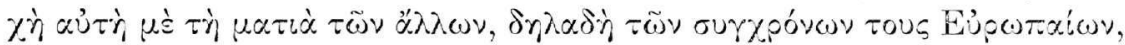

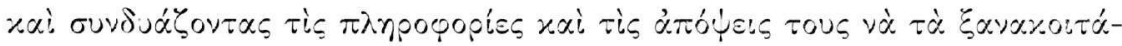

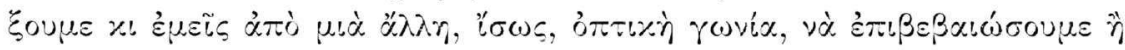

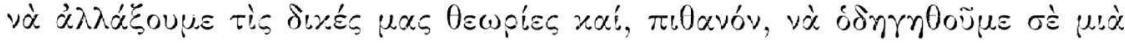

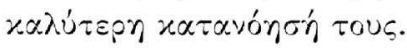

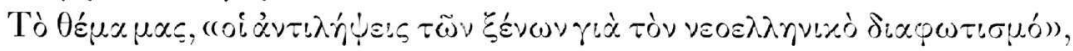

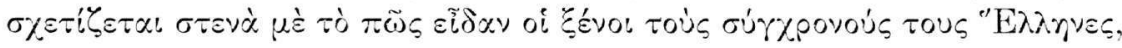

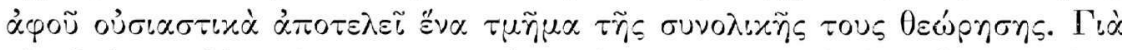

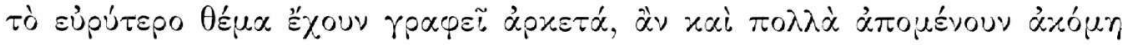

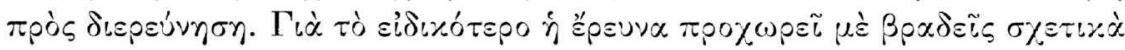
putuoús.

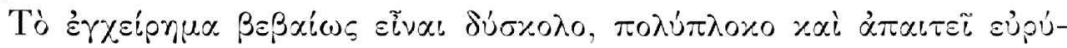

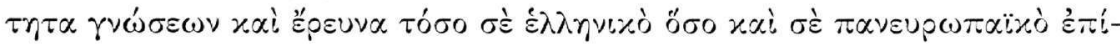

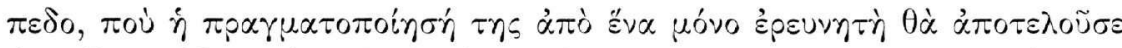

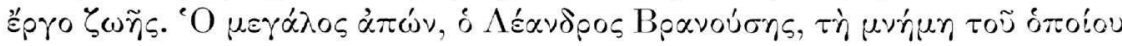

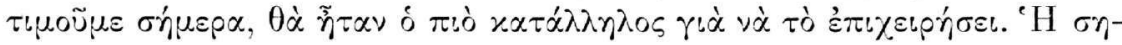

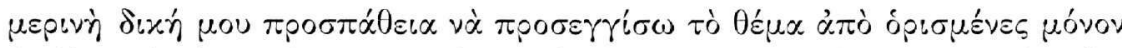

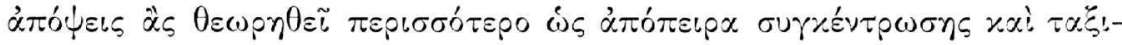

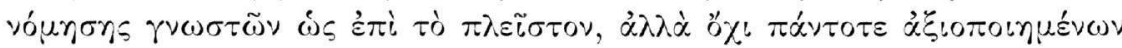

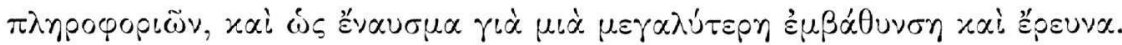

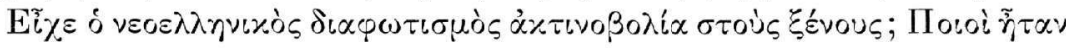

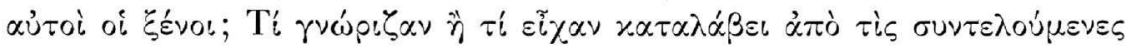

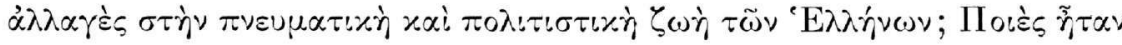




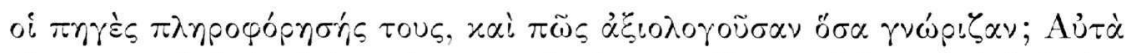

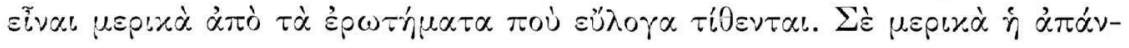

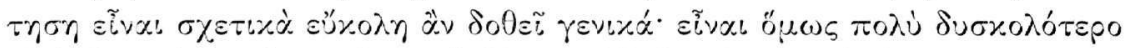

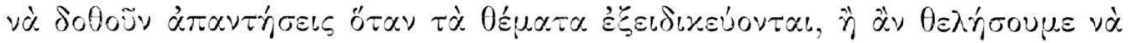

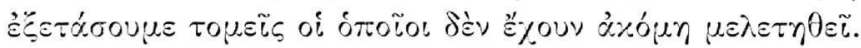

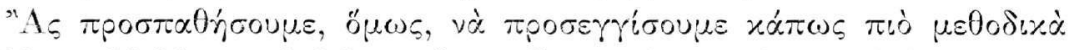

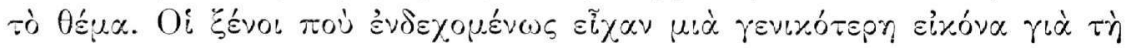

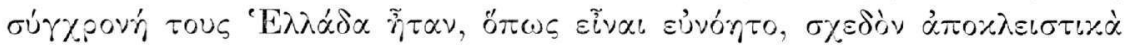

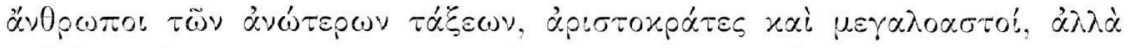

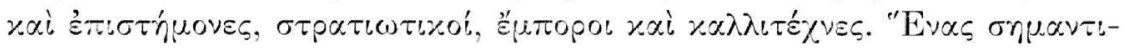

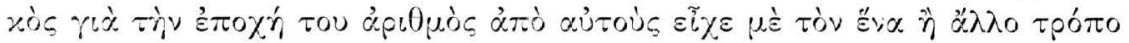

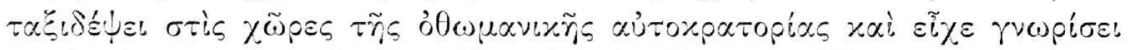

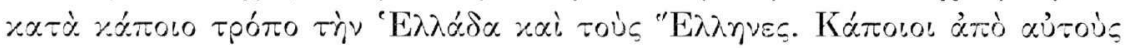

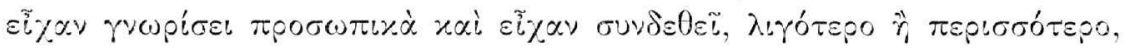

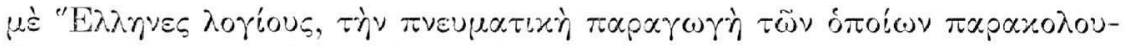

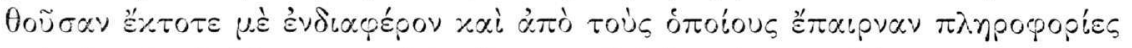

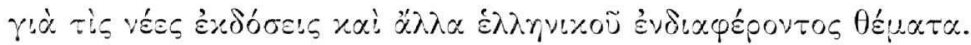

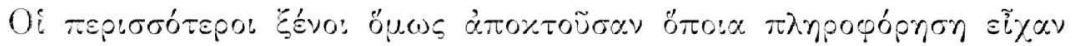

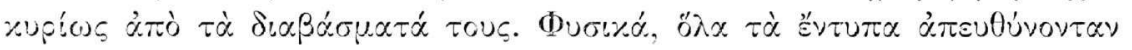

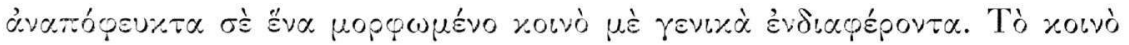

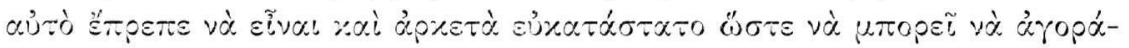

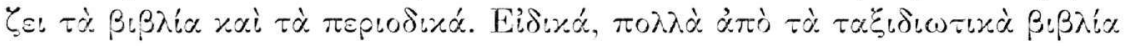

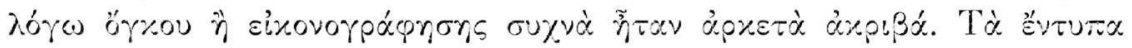

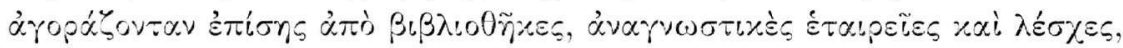

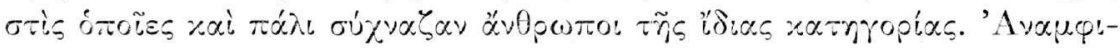

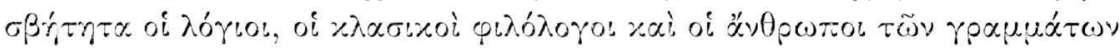

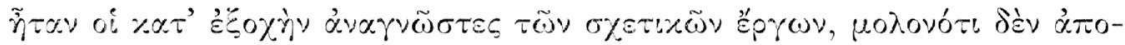

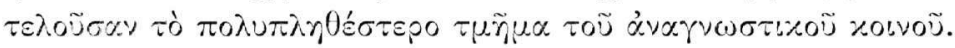

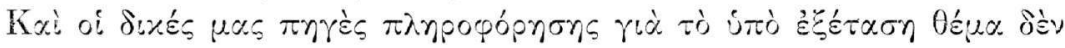

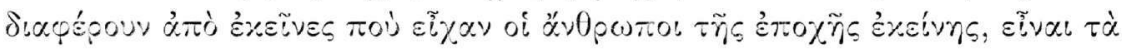

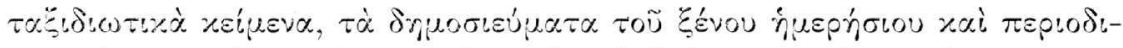

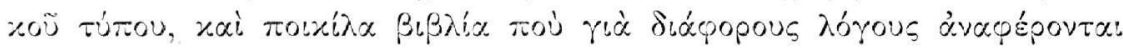

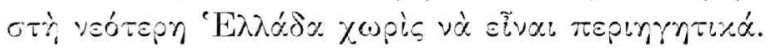

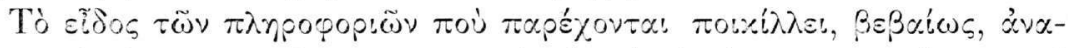

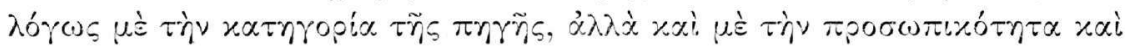

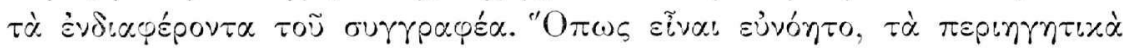

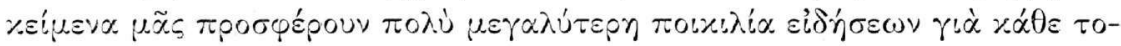

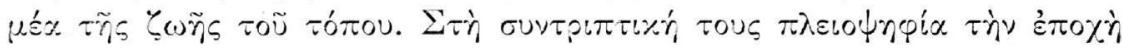




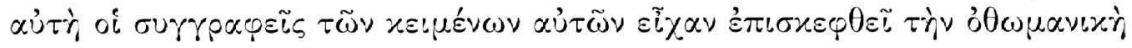

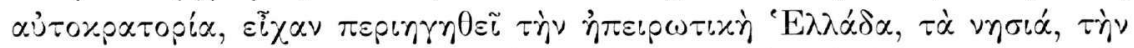

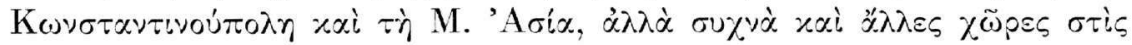

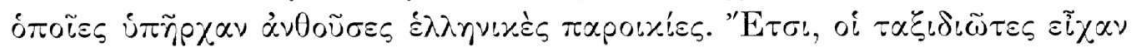

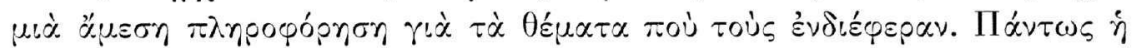

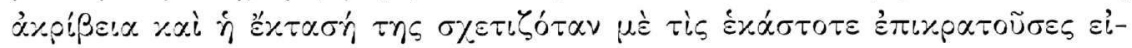

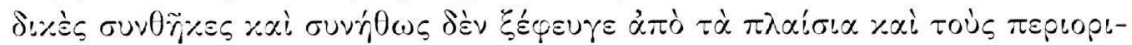

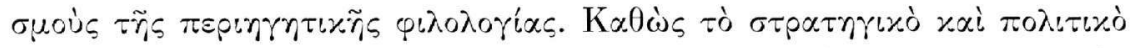

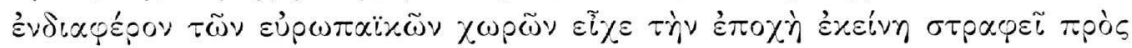

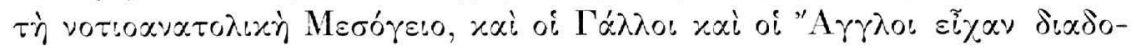

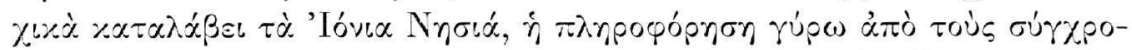

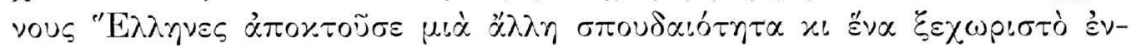

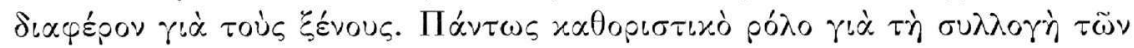

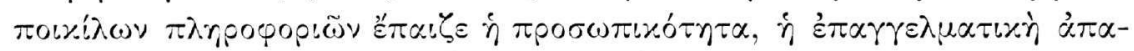

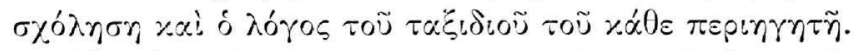

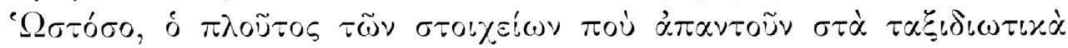

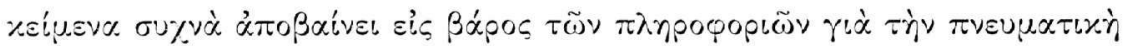

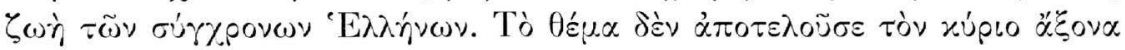

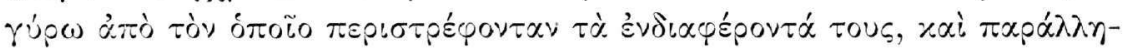

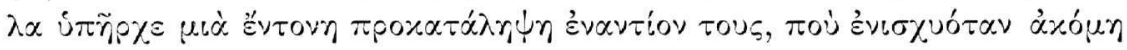

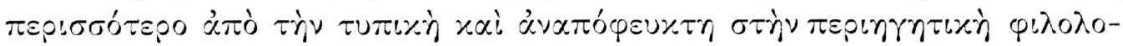

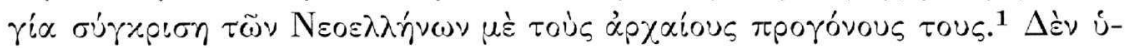

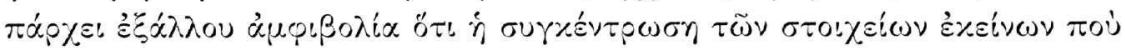

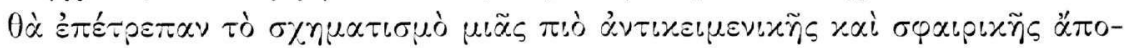

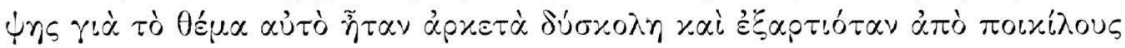

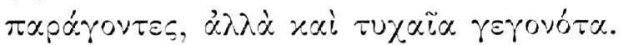

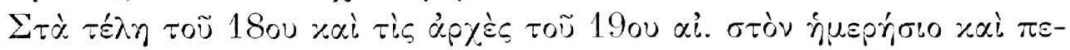

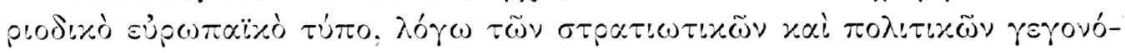

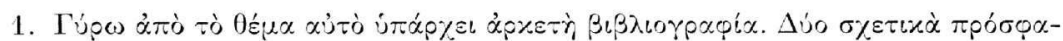

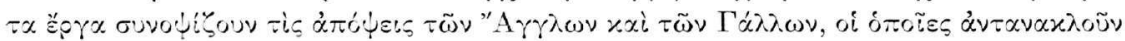

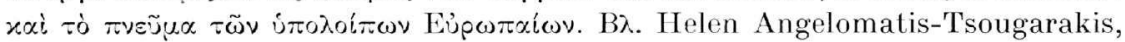
The Eve of the Greek Revival. British Travellers' Perceptions of Early Nine-

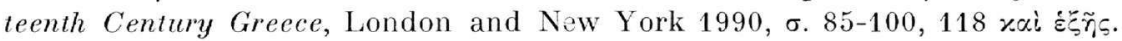
Georges Tolias, La Grèce des Hellénistes: images de la Grèce moderne dans la presse littéraire parisienne sous la Directoire, le Consulat et l'Empire (17941815), Thèse pour le doctorat (nouveau régime). Université de Paris - Sorbonne, Paris IV. Institut des Études Postbysantines et Néohelléniques, Paris

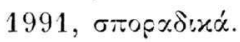




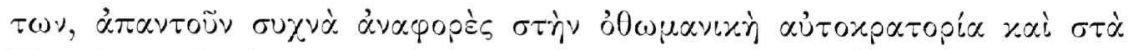

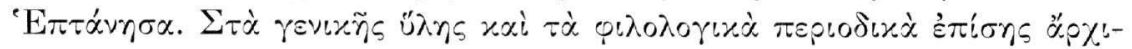

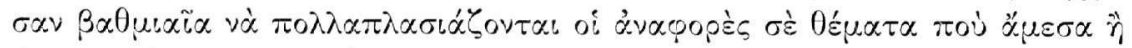

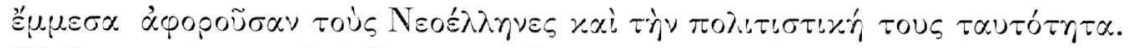

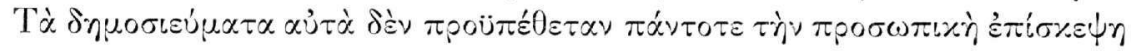

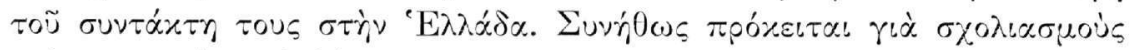

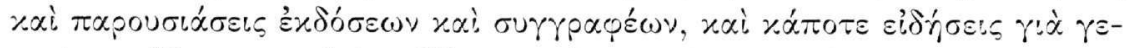

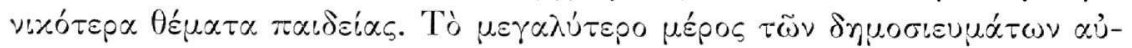

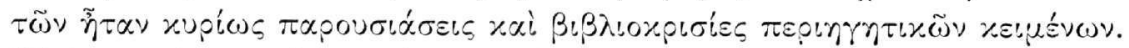

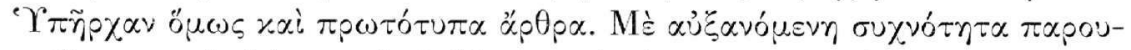

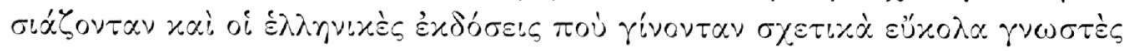

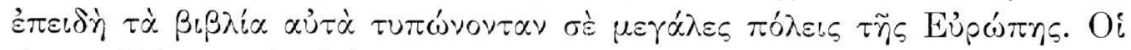

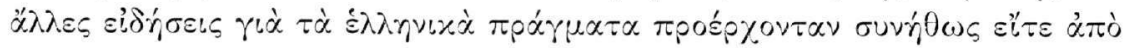

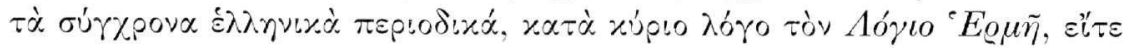

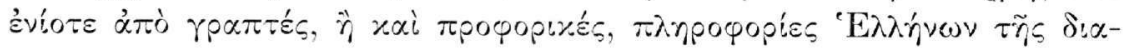
бrop $\tilde{\alpha} s$.

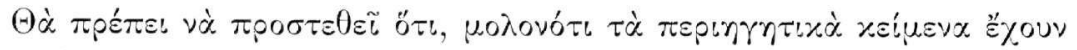

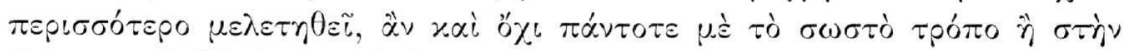

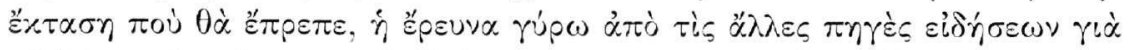

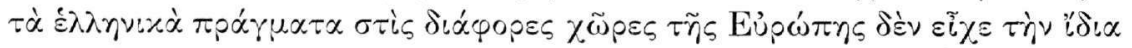

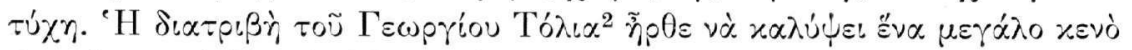

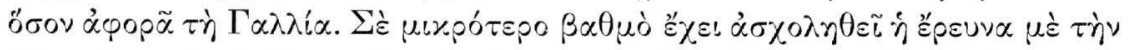

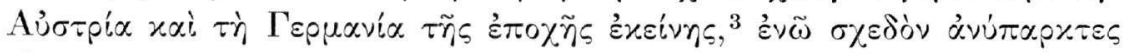

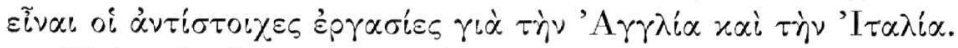

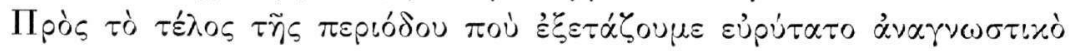

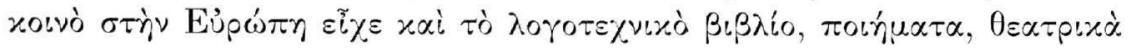

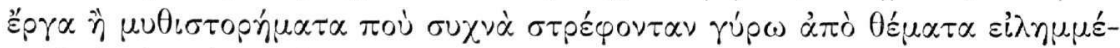

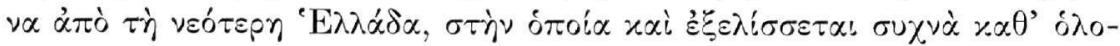

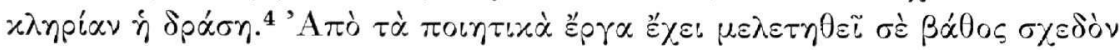

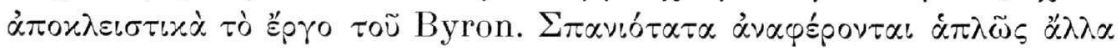

2. "O.

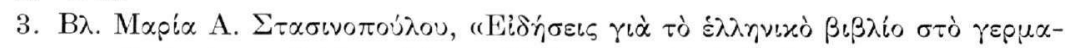

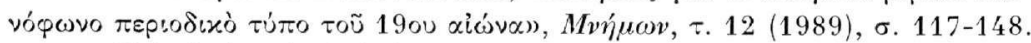

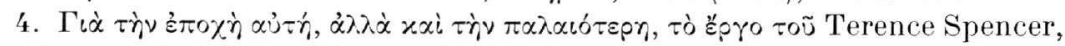
Fair Greece! Sad Relic. Literary Philhellenism from Shakespeare to Byron,

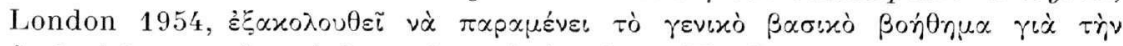
$\dot{\alpha} \gamma \gamma \lambda \iota x \dot{\eta}$ 


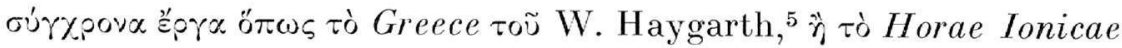

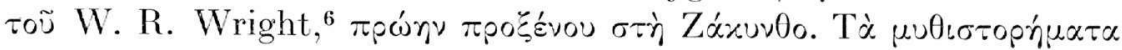

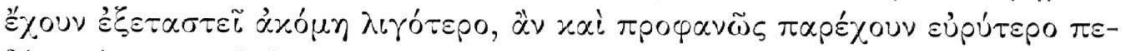

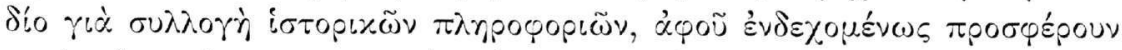

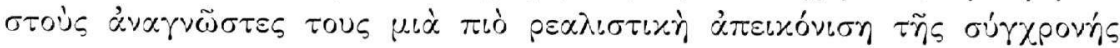

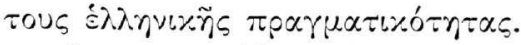

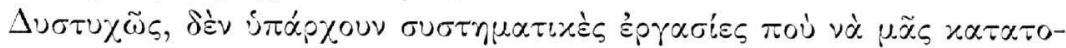

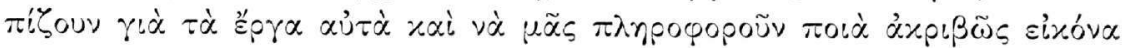

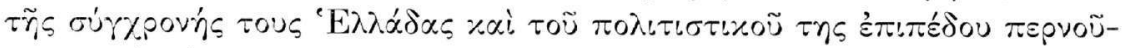

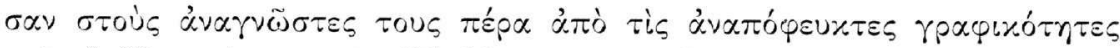

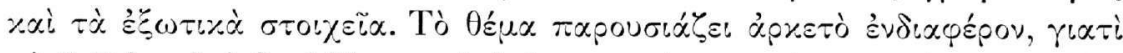

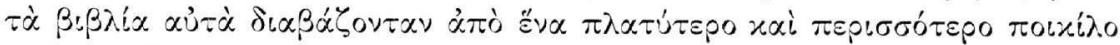

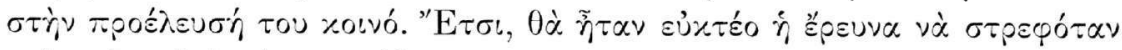

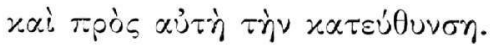

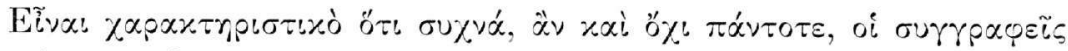

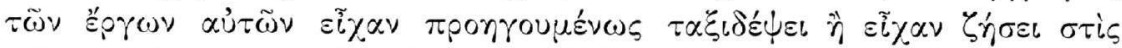

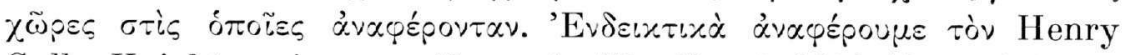

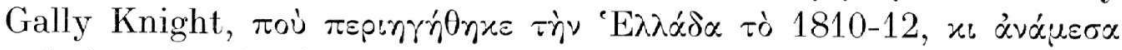

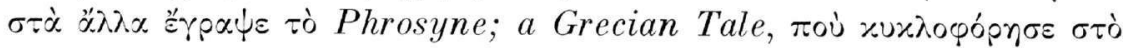

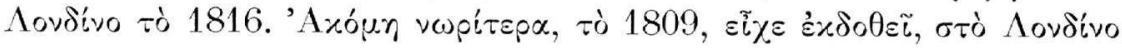

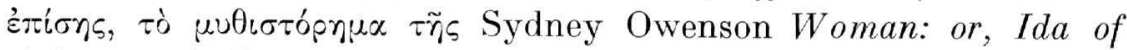

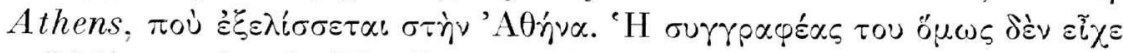

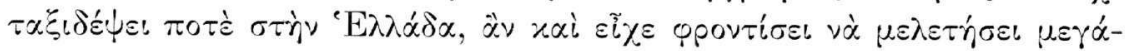

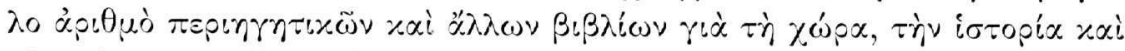

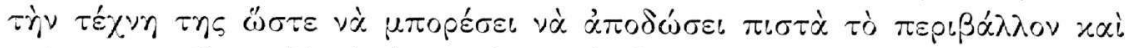

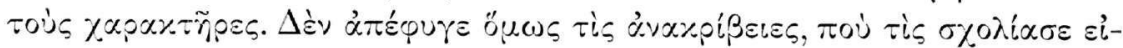

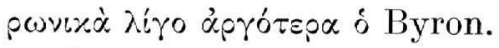

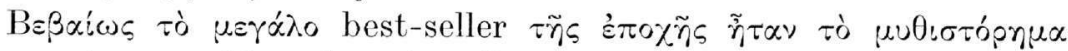
Anastasius, or, Memoirs of a Greek; written at the close of the

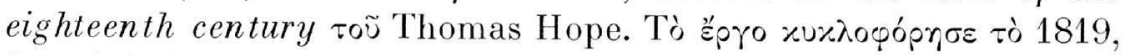

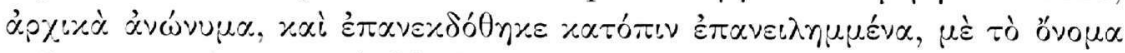

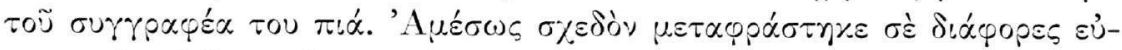

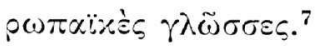

5. W. Haygarth, Greece, A Poem in Three Parts with Notes, Classical Illustrations and Sketches of the Scenery, London 1814.

6. Horae Ionicae: a Poem descriptive of the Ionian Islands and Part of the Adjacent Coast of Greece..., London 1809.

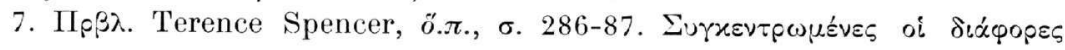




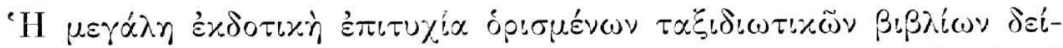

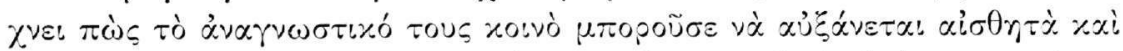

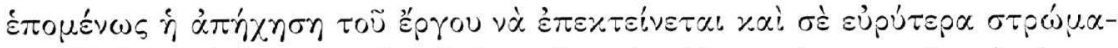

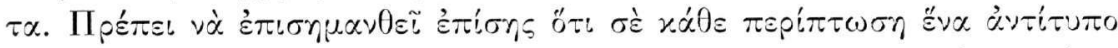

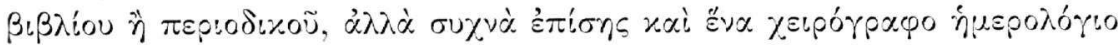

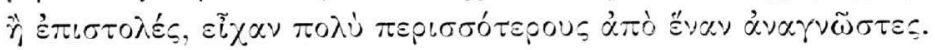

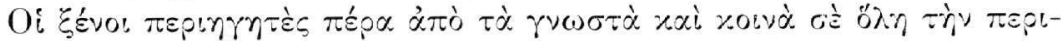

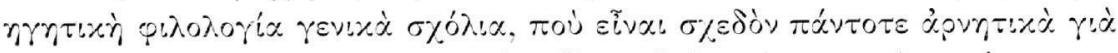

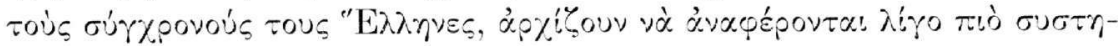

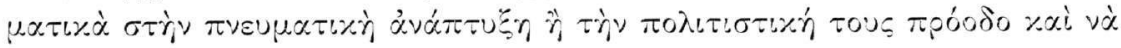

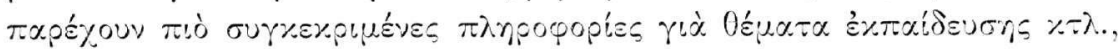

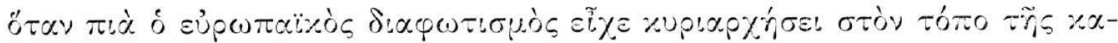

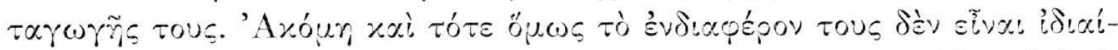

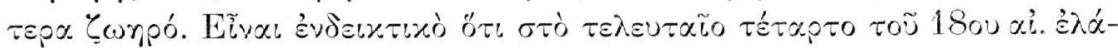

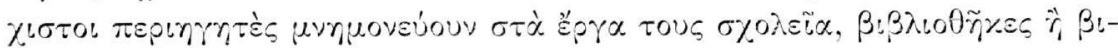

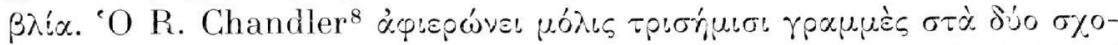

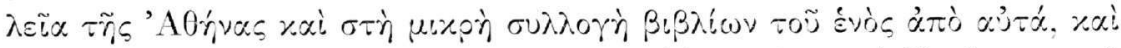

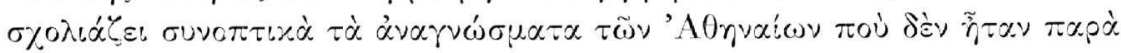

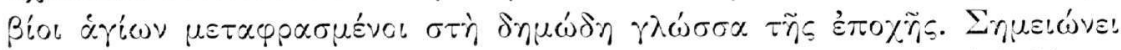

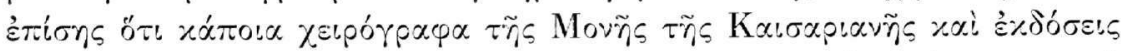

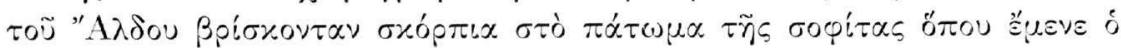
ทंYoúusvós tns.

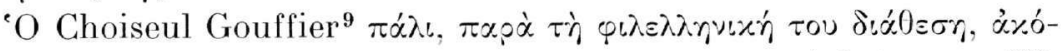

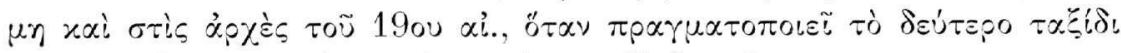

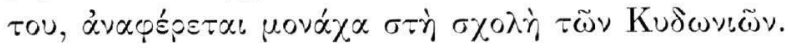

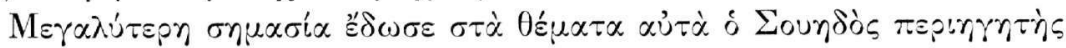

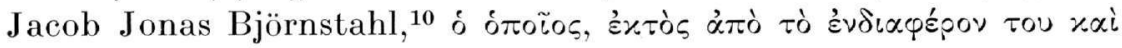

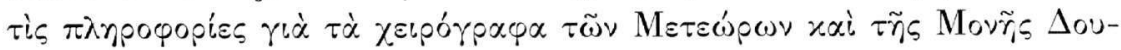

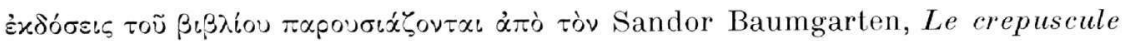

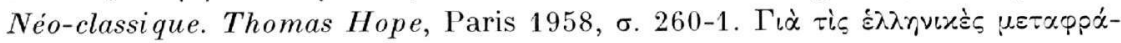

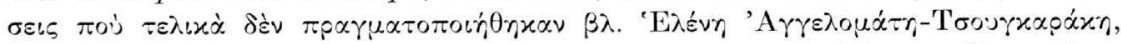
“'A

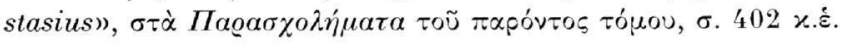

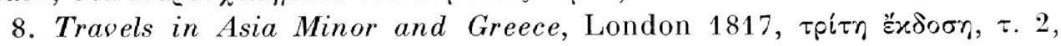
б. $137,154$.

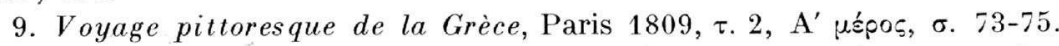

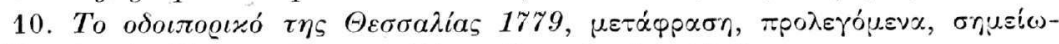

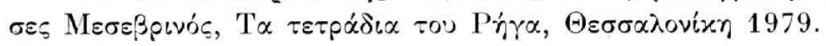




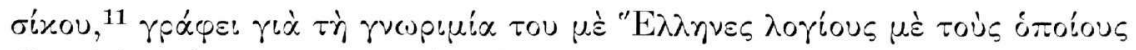

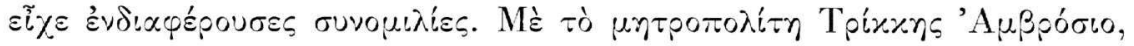

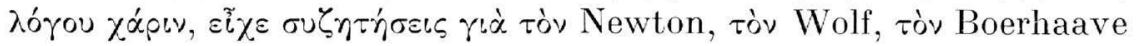

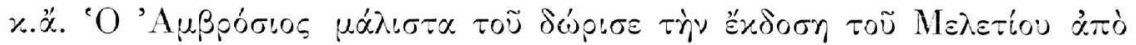

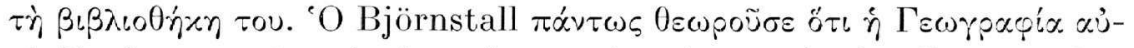

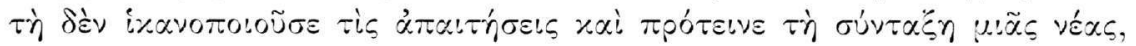

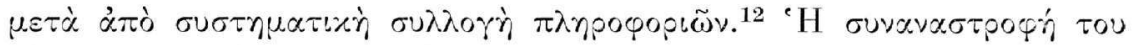

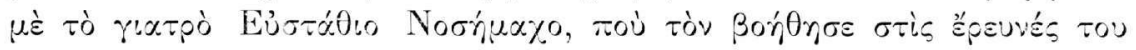

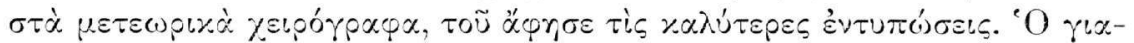

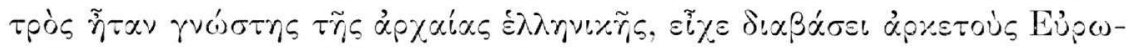

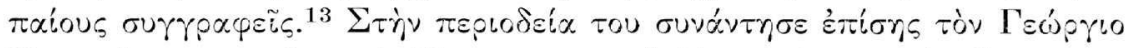

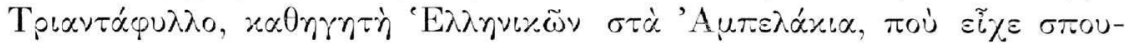

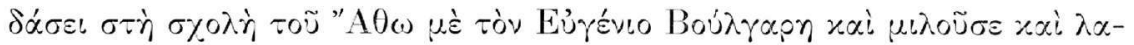

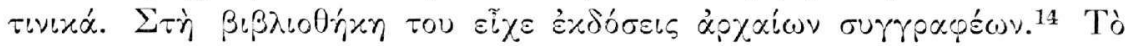

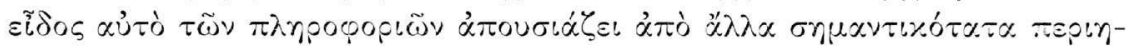

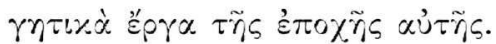

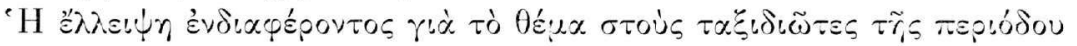

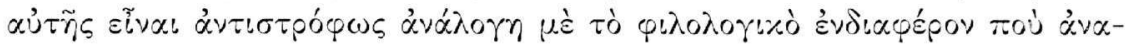

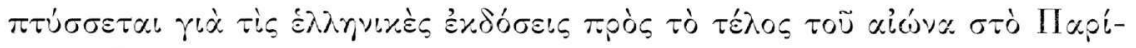

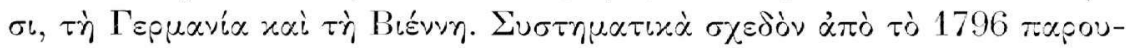

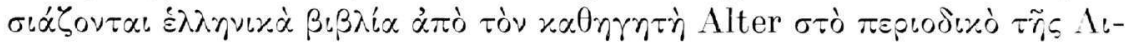

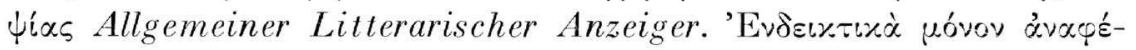

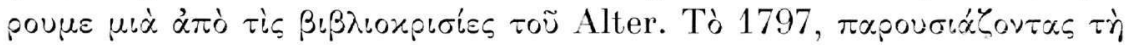

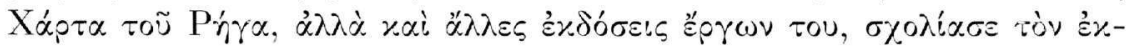

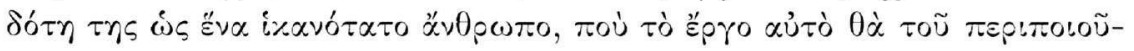

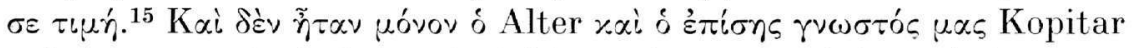

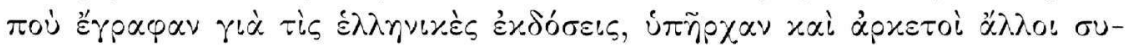

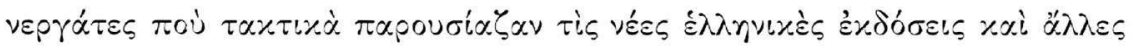

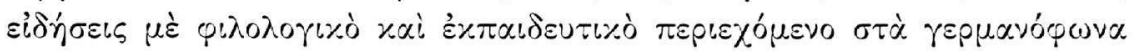

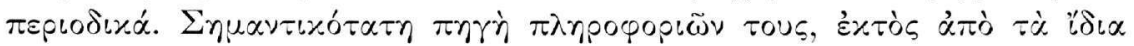

11. "O.л., б. 73-76, 80, 83-84, 87, 88-89, 93, 95-97, 99, 104-9.

12. "O.л., б. 69, 127, 142.

13. "O.л., $\sigma .82,88,89$.

14. "O.л., б. 125, 126.

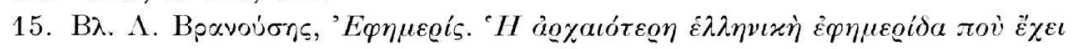

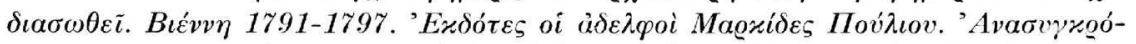

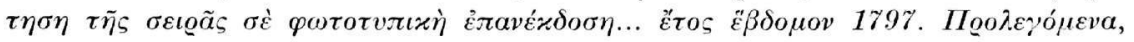
'A $\theta \dot{v} v \alpha$ 1995, б. 308, 630, 732, 853, 854. 


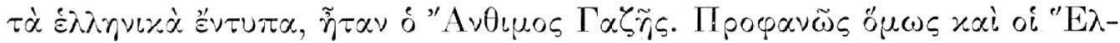

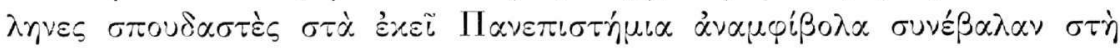

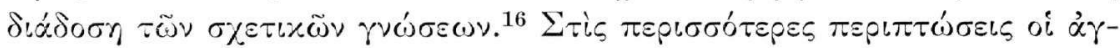

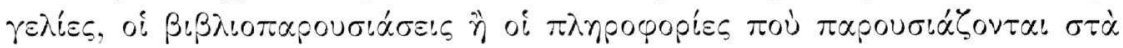

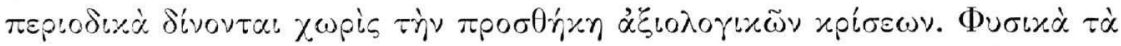

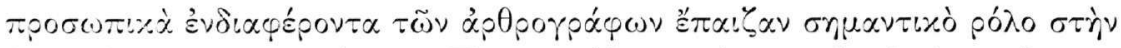

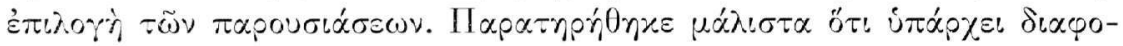

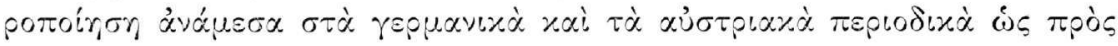

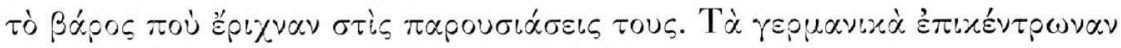

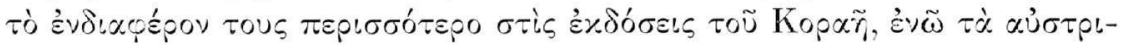

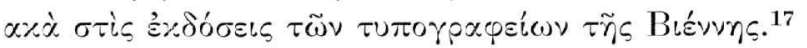

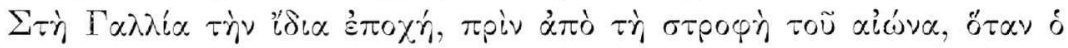

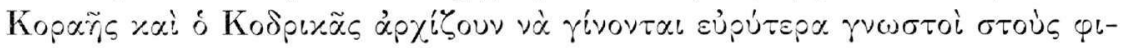

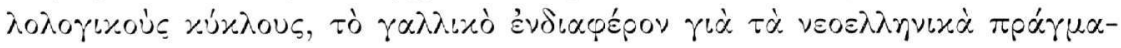

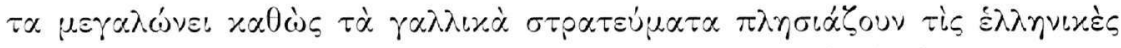

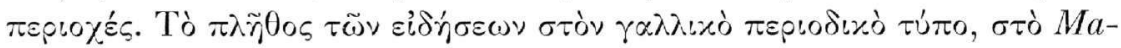

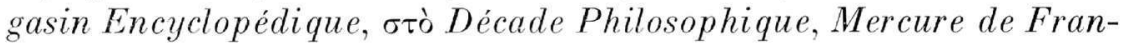

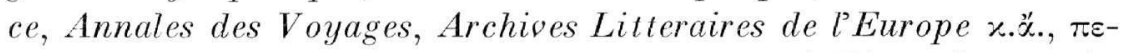

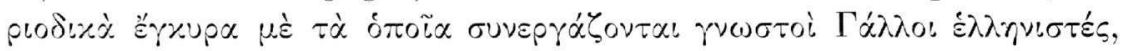

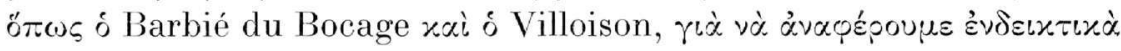

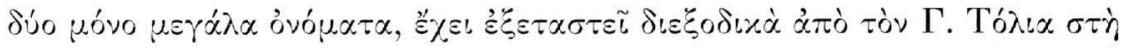

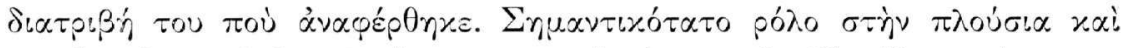

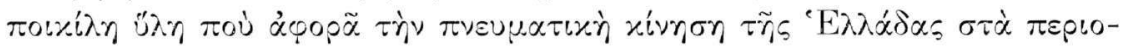

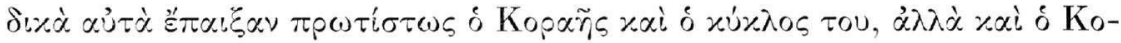

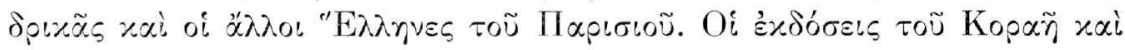

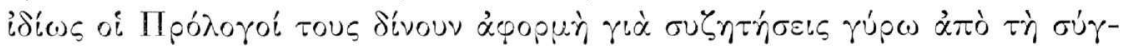
xporn ' $\mathrm{E} \lambda \lambda \alpha \dot{\alpha} \delta \alpha$.

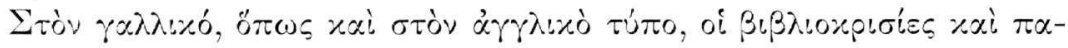

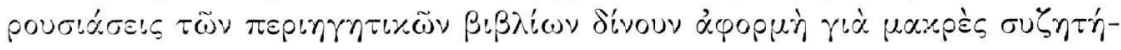

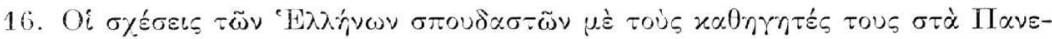

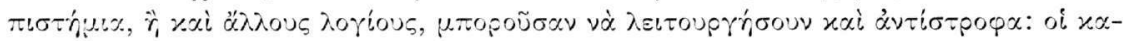

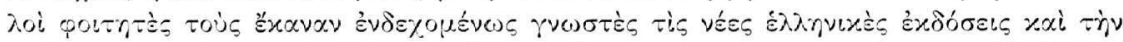

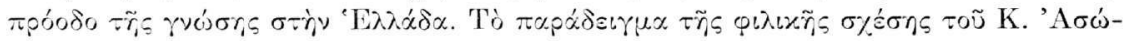

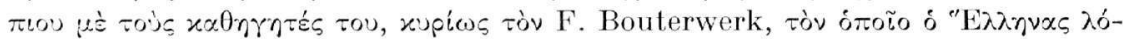

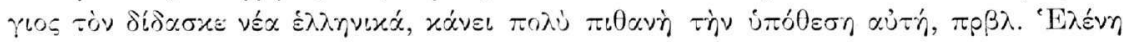

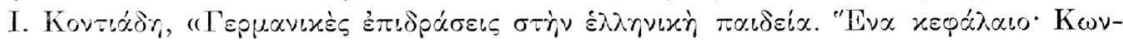

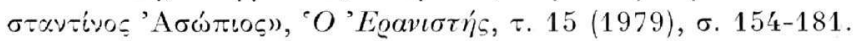

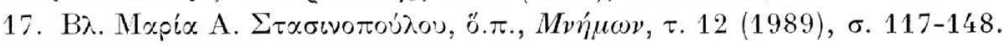




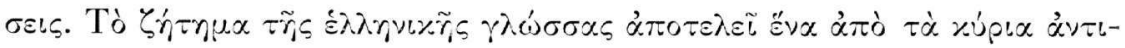

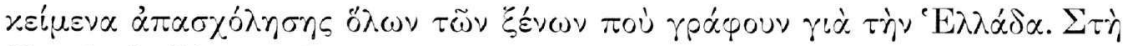

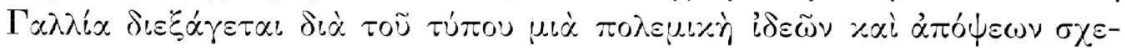

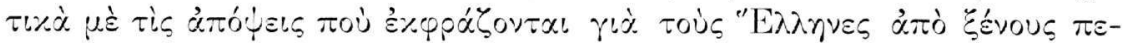

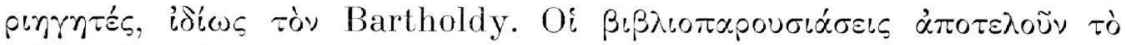

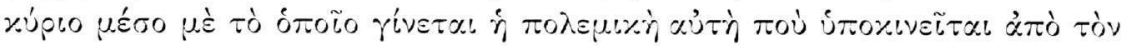

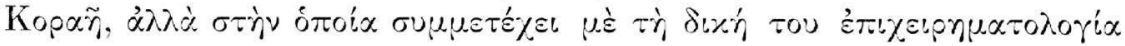

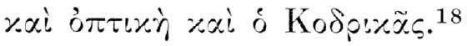

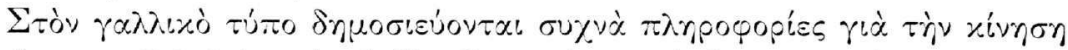

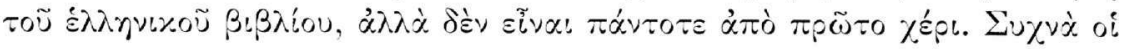

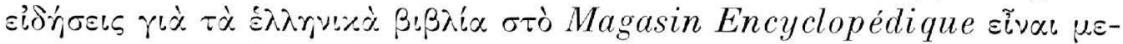

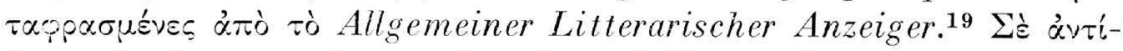

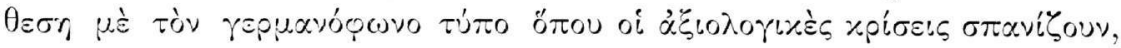

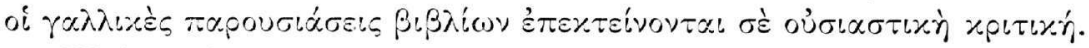

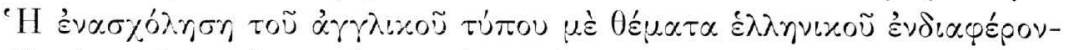

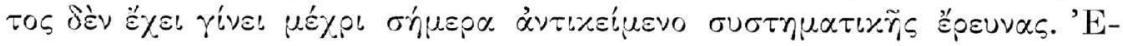

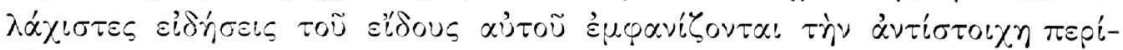

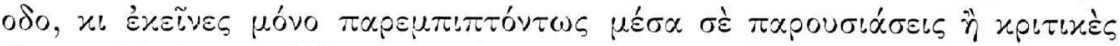

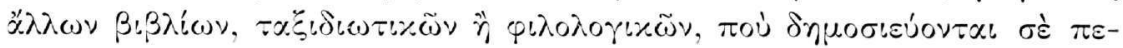

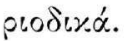

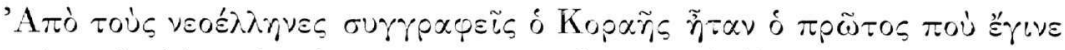

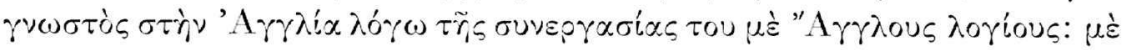

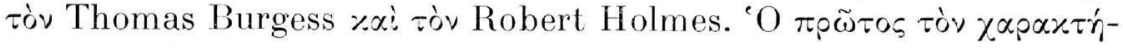

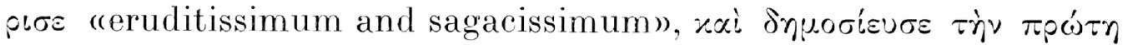

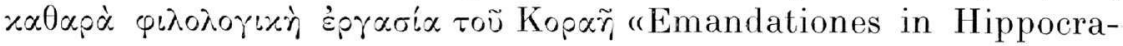

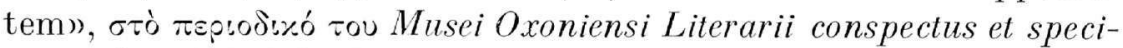

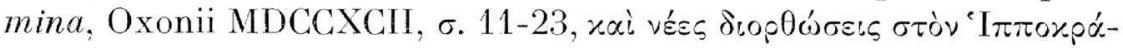

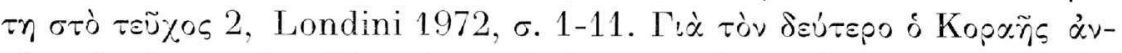

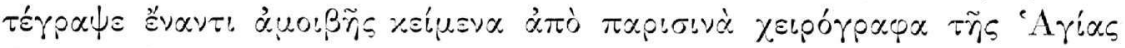

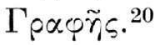

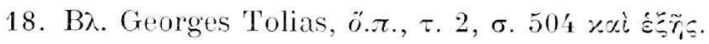
608.

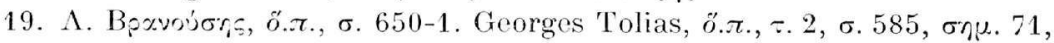

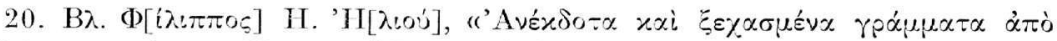

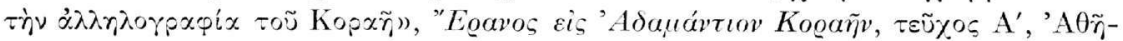

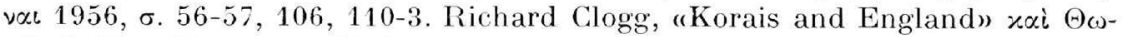

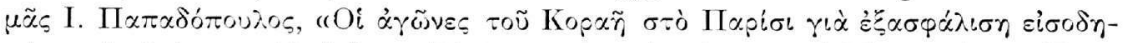

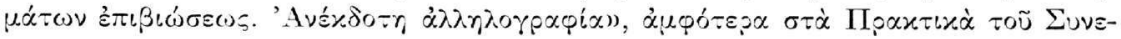




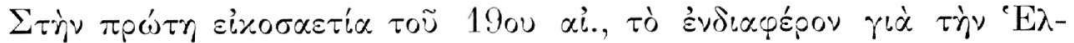

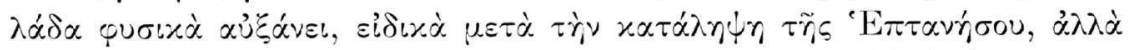

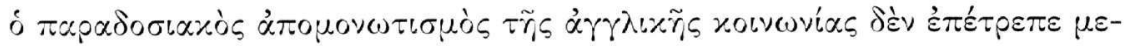

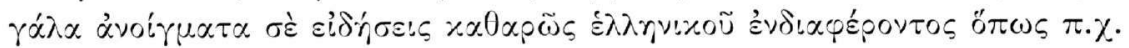

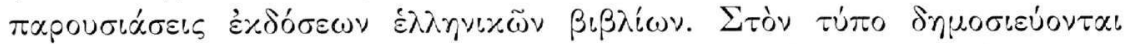

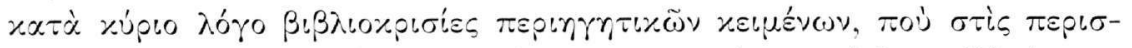

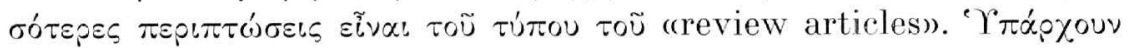

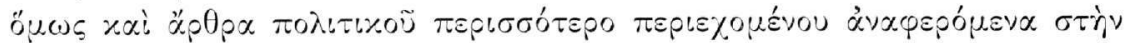

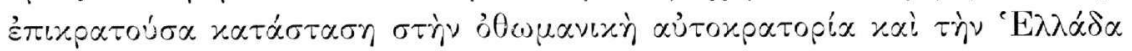

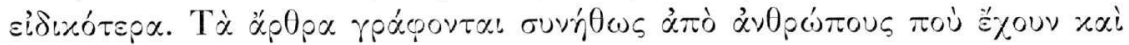

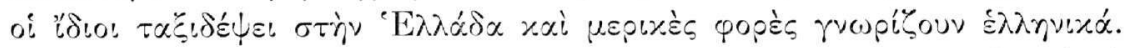

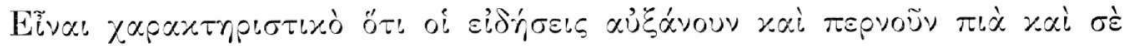

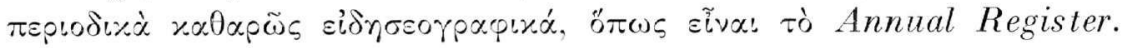

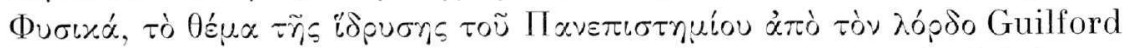

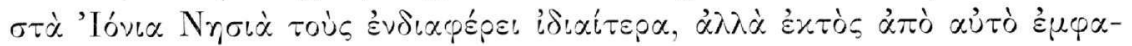

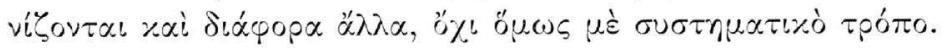

Пó

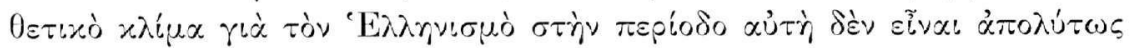

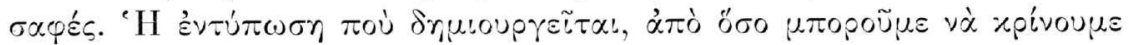

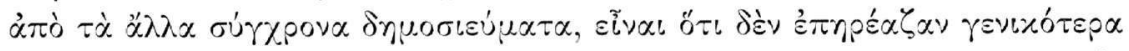

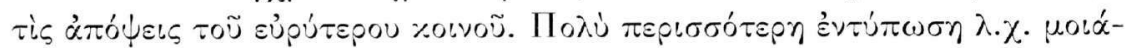

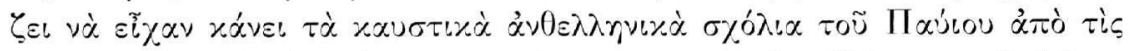

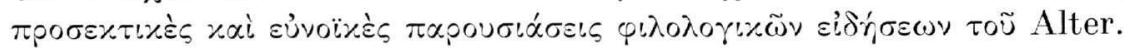

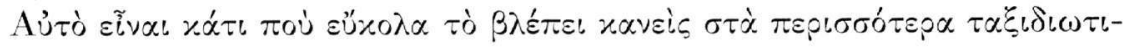
$\chi \dot{\alpha} \beta, \beta \lambda i \alpha$.

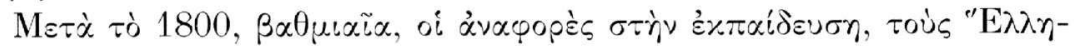

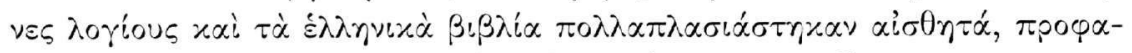

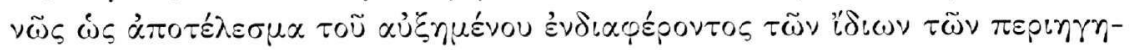

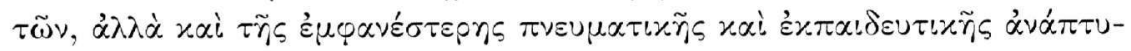

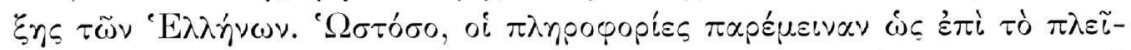

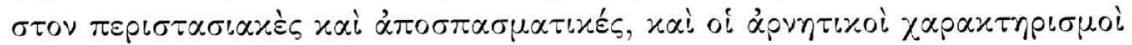

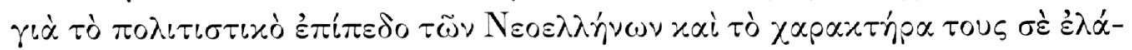

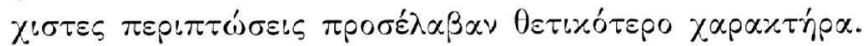

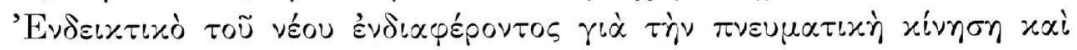

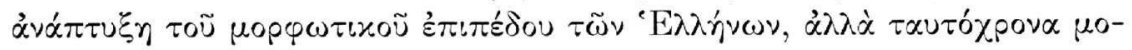

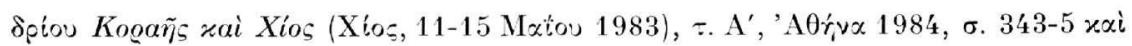

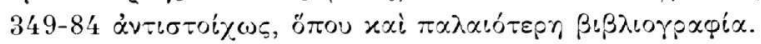




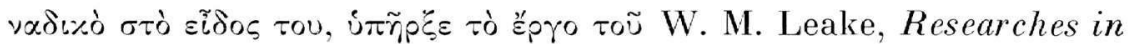

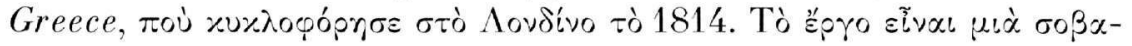

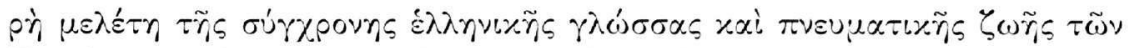

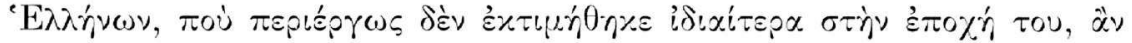

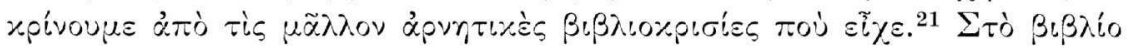

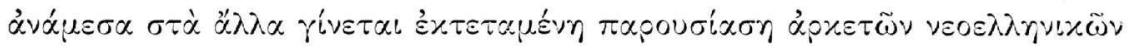

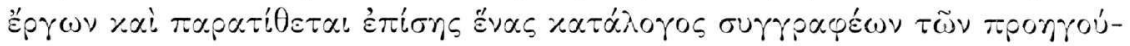

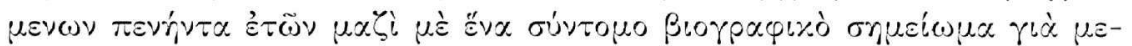

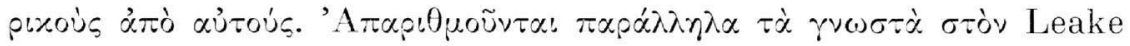

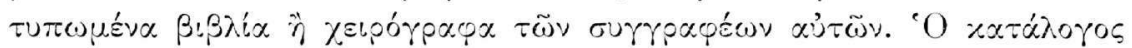

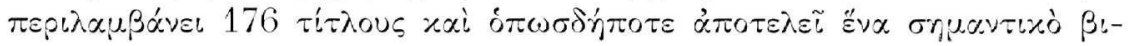

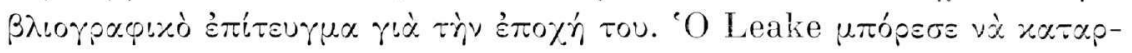

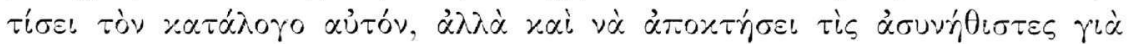

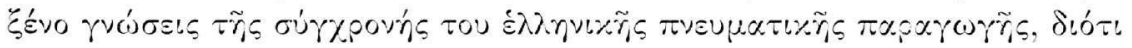

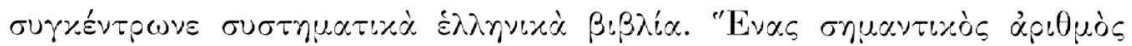

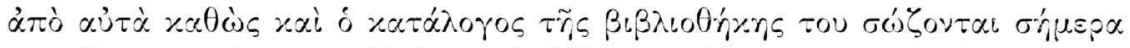

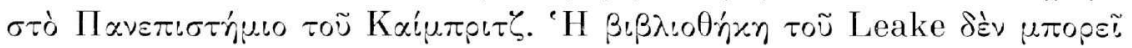

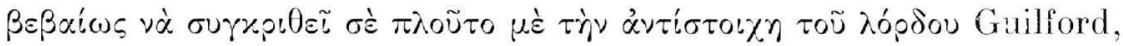

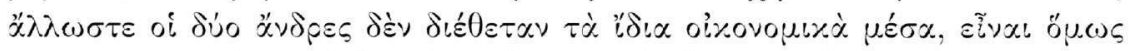

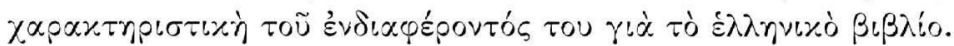

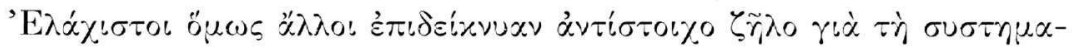

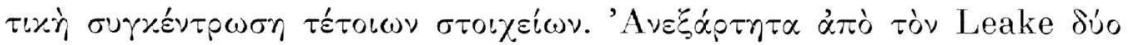

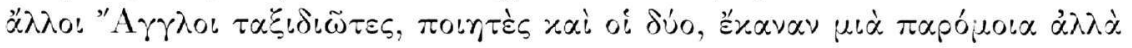

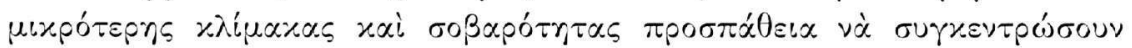

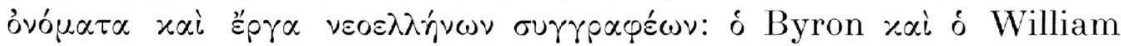

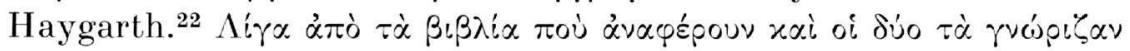

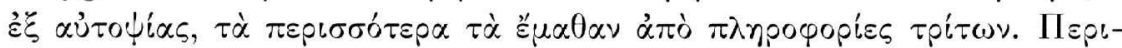

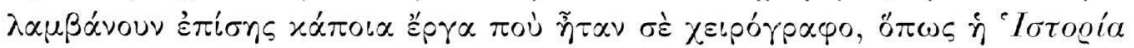

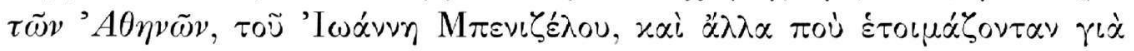

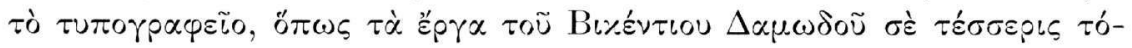

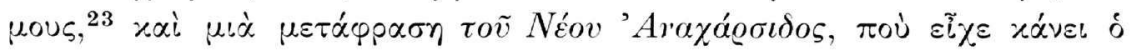

21. The Edinburgh Review, $\tau$. XXIV (1815), б. 353-69. The Quarterly Review, $\tau$. XI (1814), б. 458-80.

22. Childe Harold's Pilgrimage, a romaunt and other poems, London

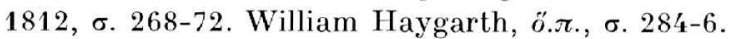

23. W. Haygarth, ö.л., б. 285. 


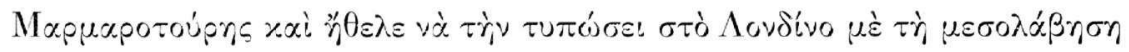
$\tau o \tilde{~ B y r o n . ~}{ }^{24}$

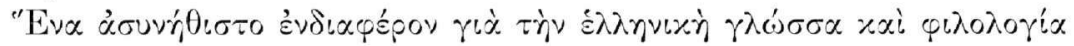

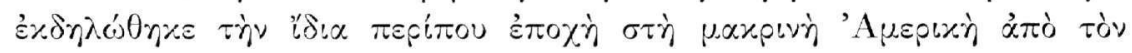

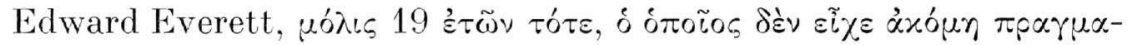

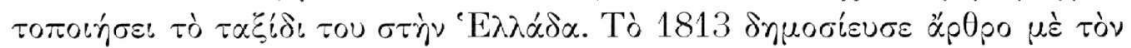
$\tau i \tau \lambda \circ$ (On the Literature and Language of Modern Greece». ${ }^{25} \Pi_{\eta \gamma} \gamma \grave{\varepsilon}$

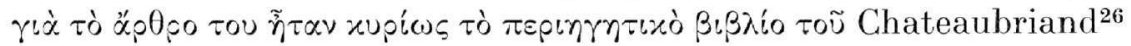

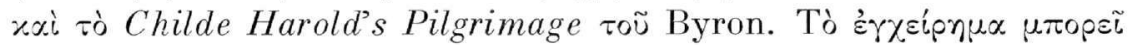

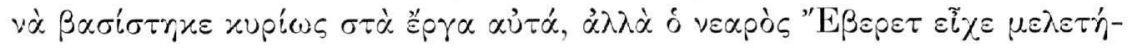

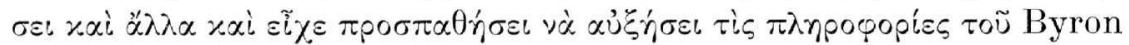

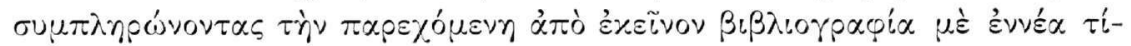

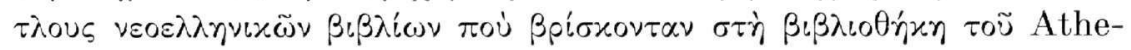

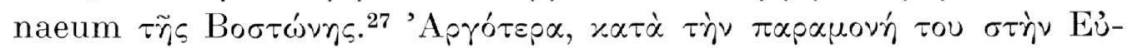

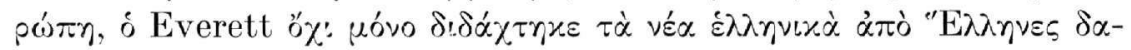

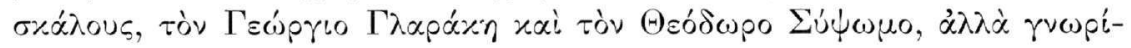

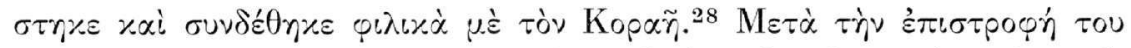

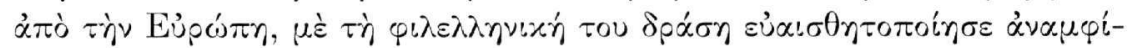

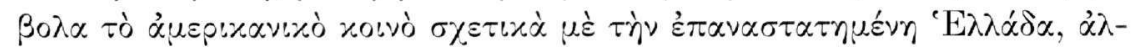

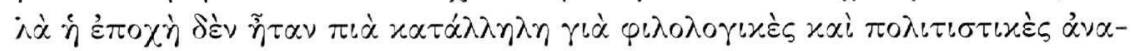

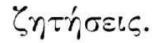

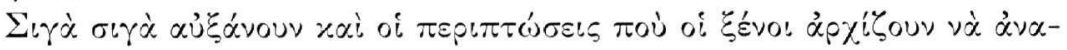

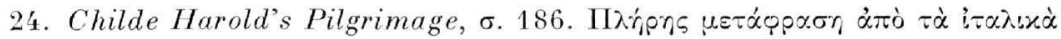

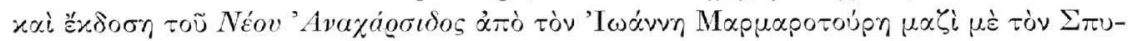

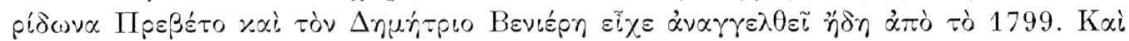

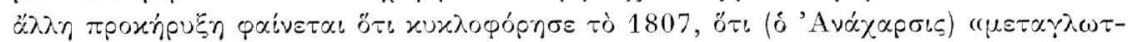

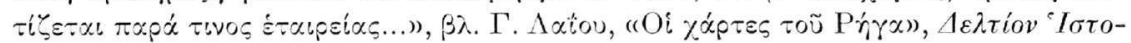

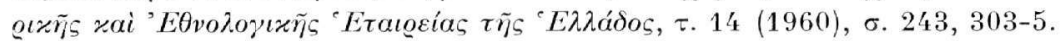

25. The General Repository and Review, Cambridge Massachusetts, $\tau$.

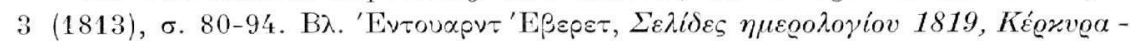

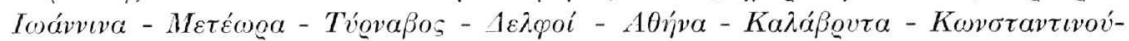

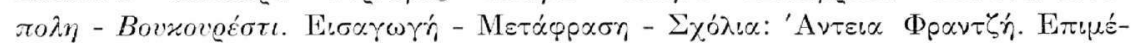

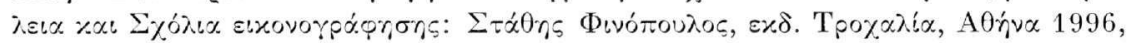

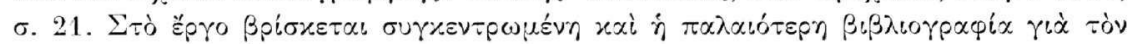
Everett.

26. Itinéraire de Paris à Jérusalem et de Jérusalem à Paris, en allant par la Grèce, et en revenant par l'Egyp te, la Barbarie et l'Espagne, Paris 1811.

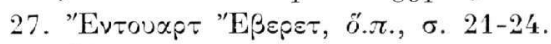

28. "O. $\pi .$, , $27-30$. 


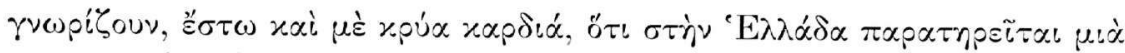

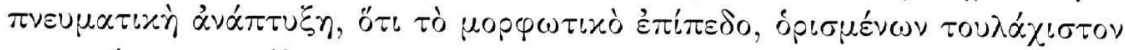

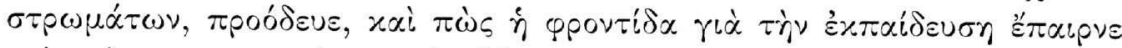

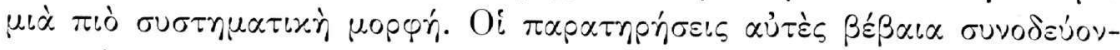

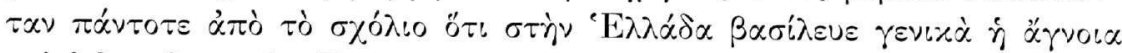

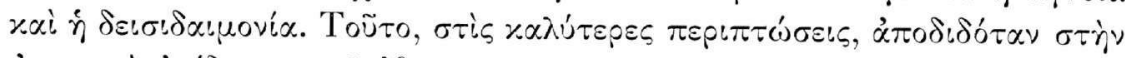

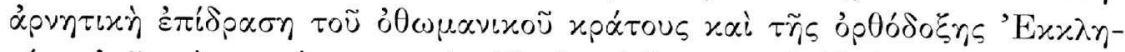

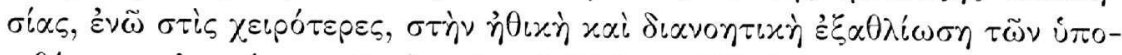

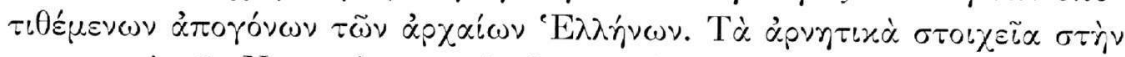

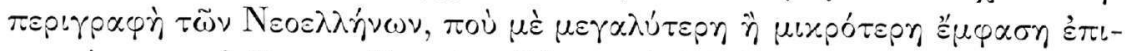

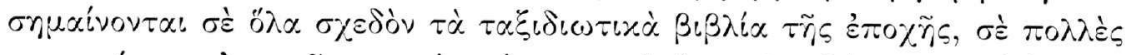

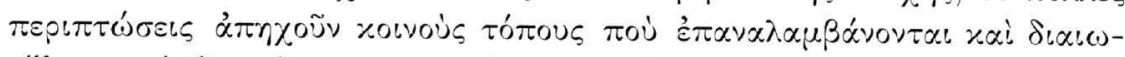

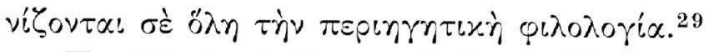

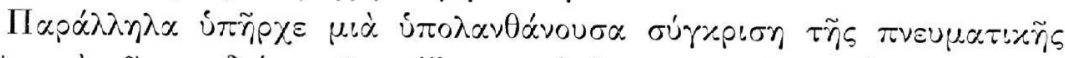

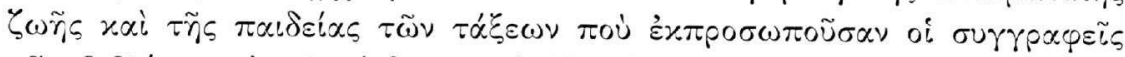

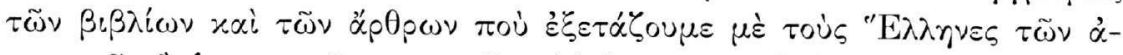

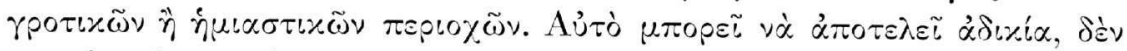

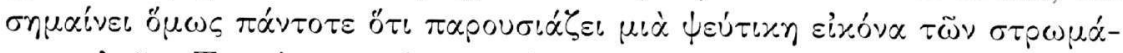

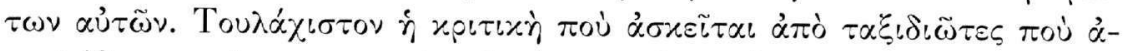

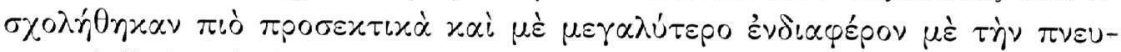

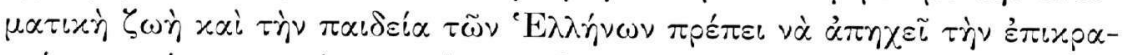

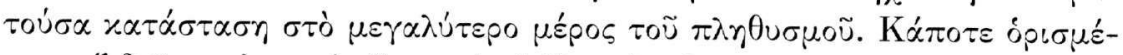

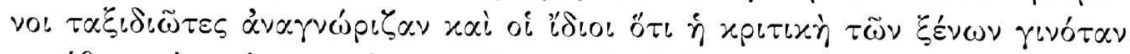

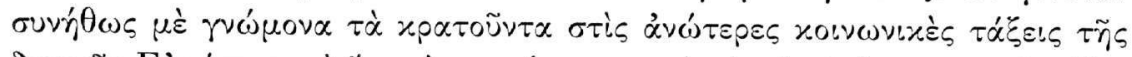

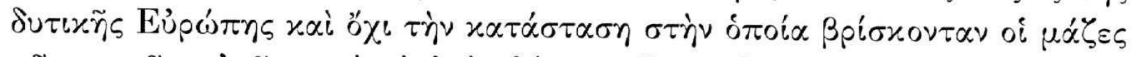

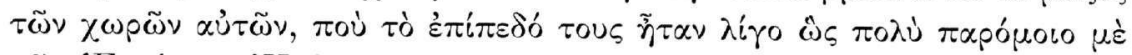

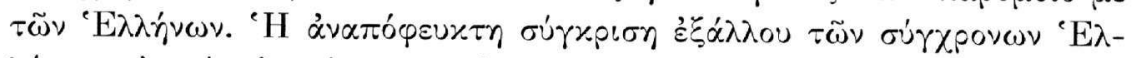

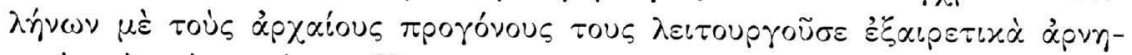

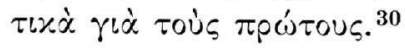

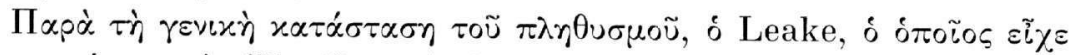

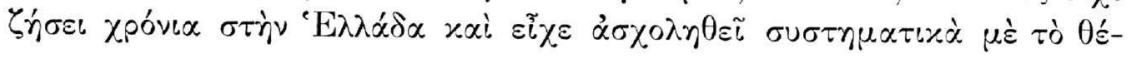

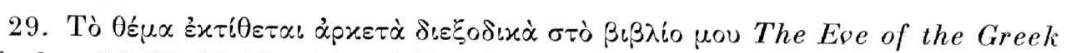

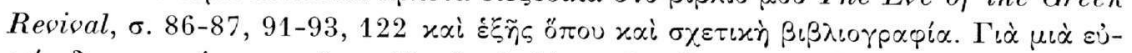

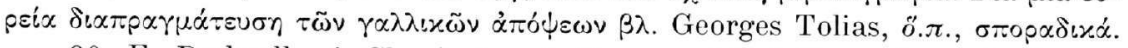

30. E. Dodwell, A Classical and Topographical Tour through Greece,

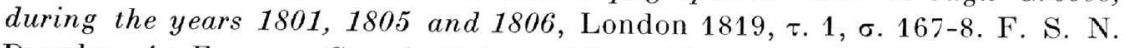
Douglas, An Essay on Certain Points of Resemblance between the Ancient and the Modern Greeks, London 1813, б. 81 . 


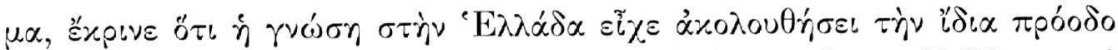

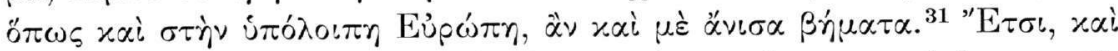

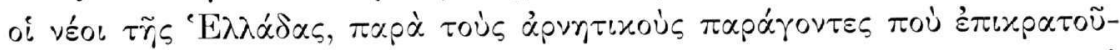

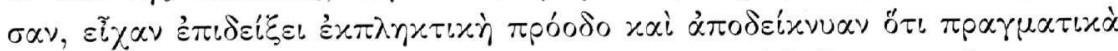

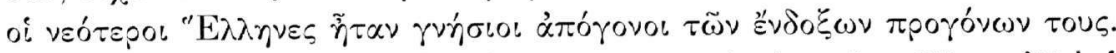

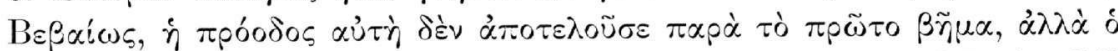

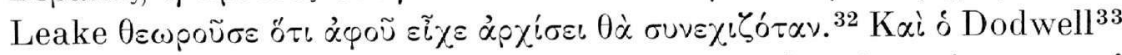

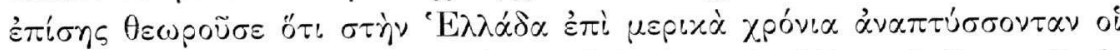

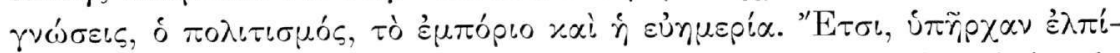

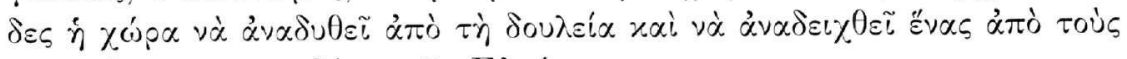
$\lambda \alpha \mu \pi \rho o ́ \tau \varepsilon \rho o u s ~ \varphi \omega \tau o \delta o ́ \tau \varepsilon s ~ \tau \tilde{r} s$ Eủpórns.

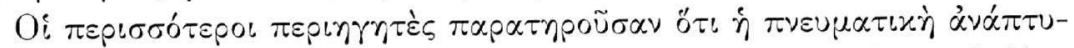

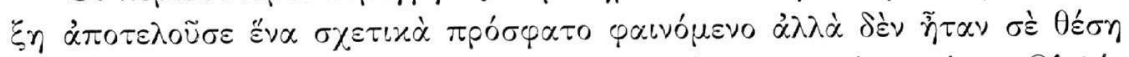

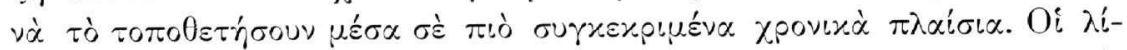

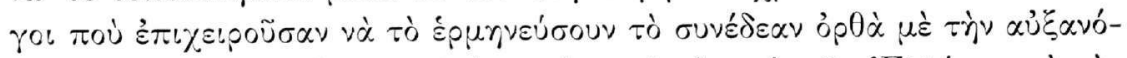

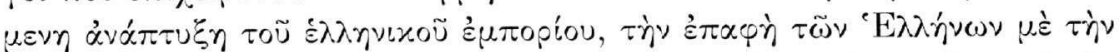

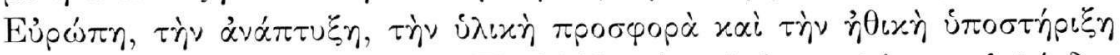

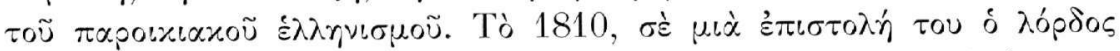

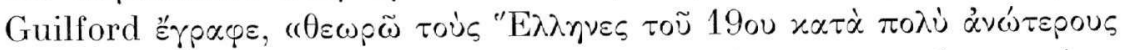

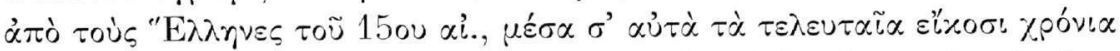

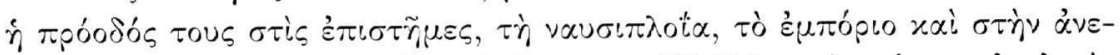

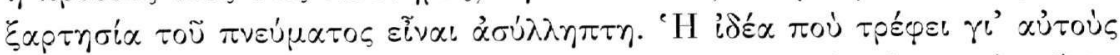

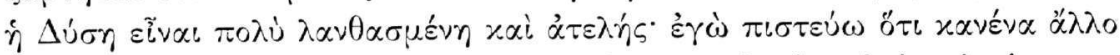

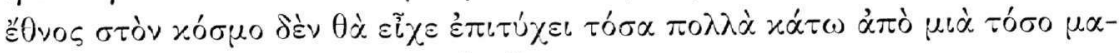

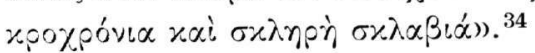

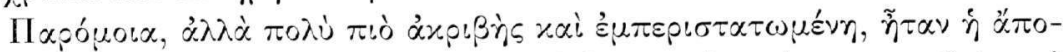

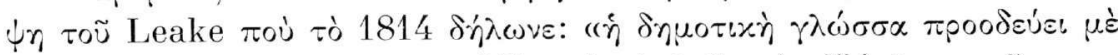

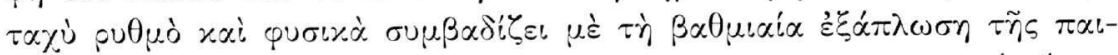

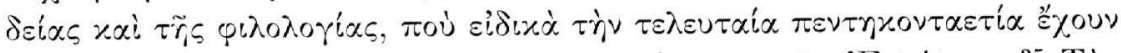

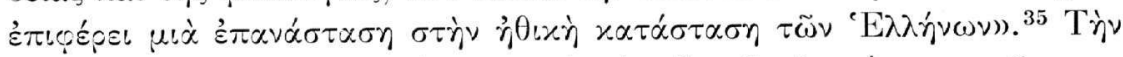

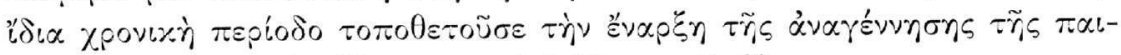

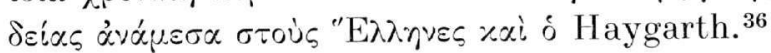

31. "O.л., б. 231 .

32. "O.л., б. 235.

33. "O.л., т. 1, б. 168.

34. British Library, Add. Ms 61981, Q. $111 \beta$.

35. "O.л., б. 226

36. "O.л., б. 282 


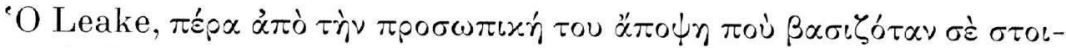

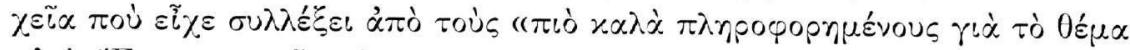

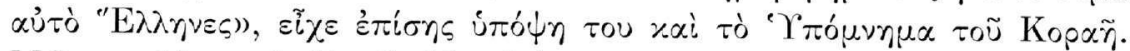

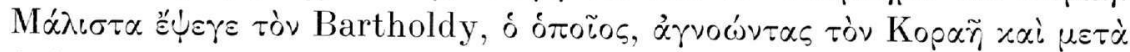

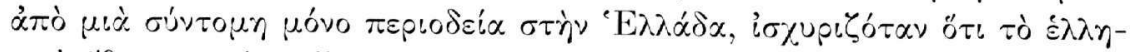

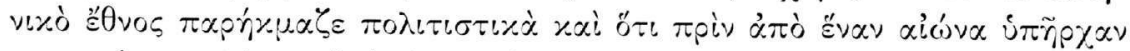

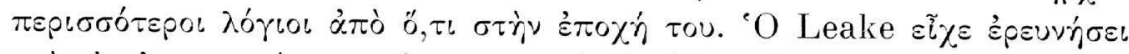

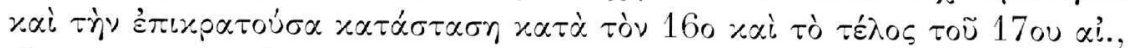

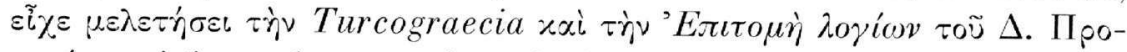

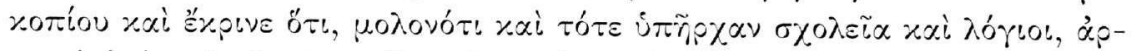

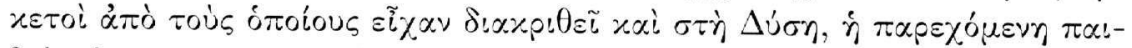

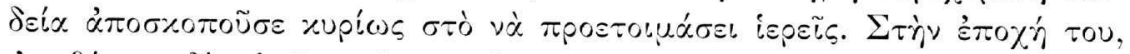

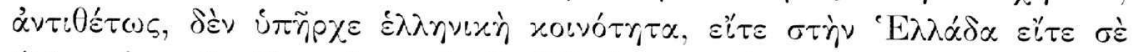

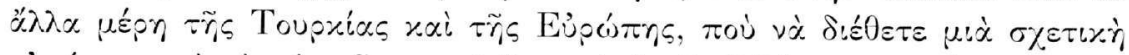

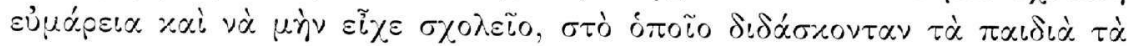

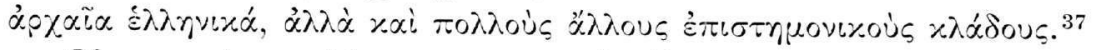

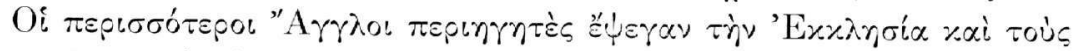

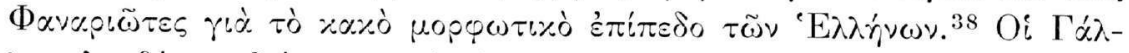

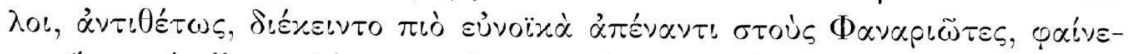

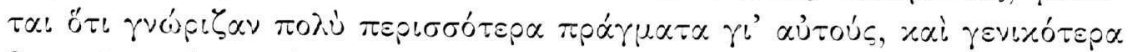

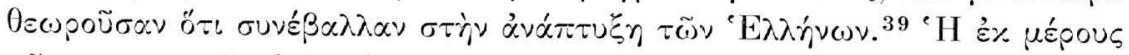

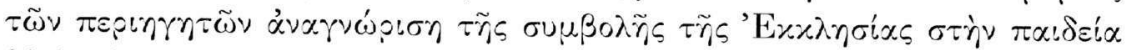

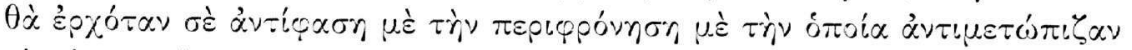

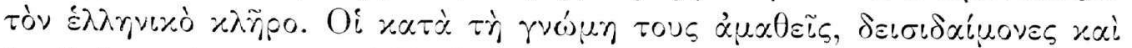

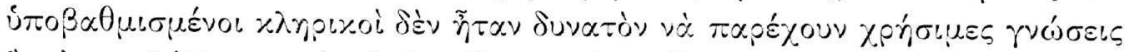

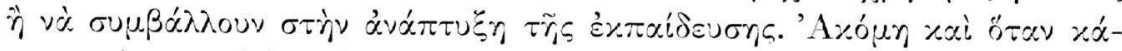

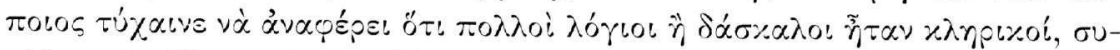

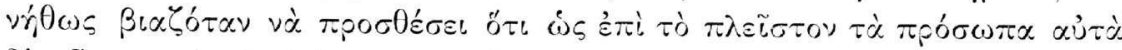

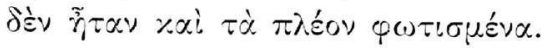

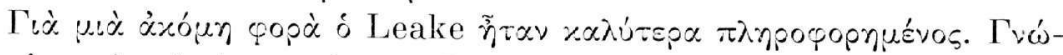

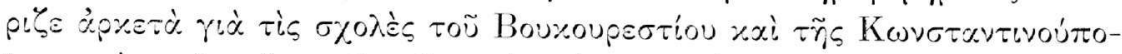

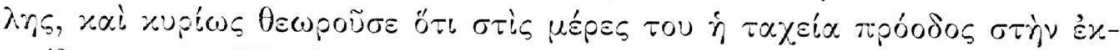

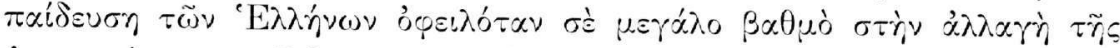

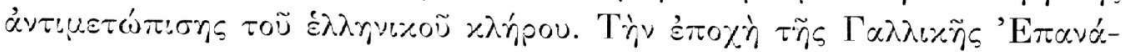

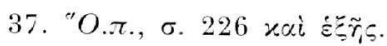

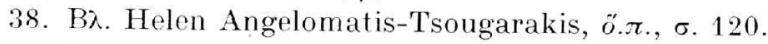

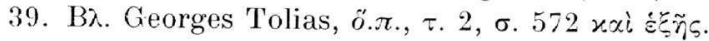




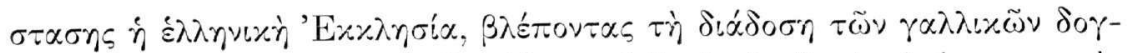

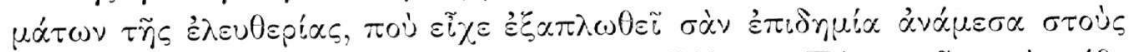

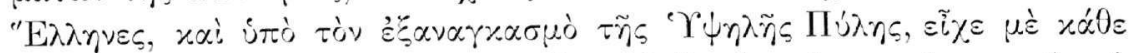

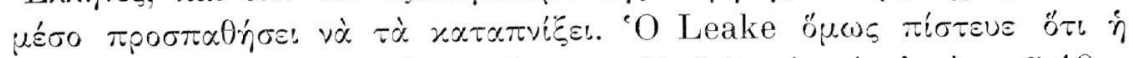

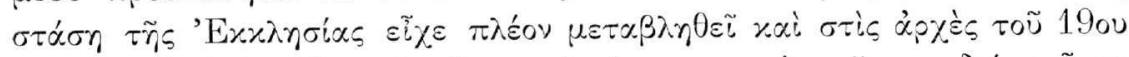

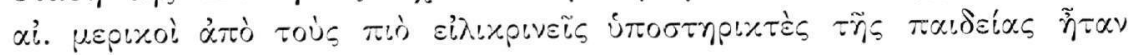

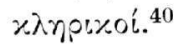

Тò

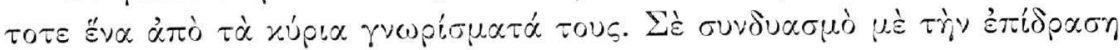

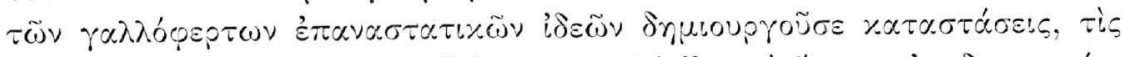

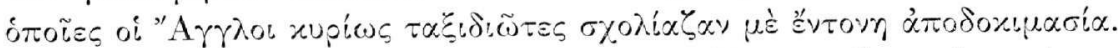

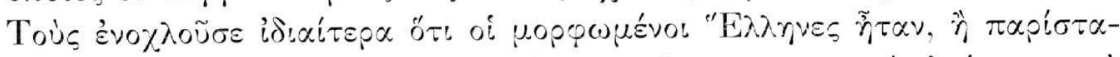

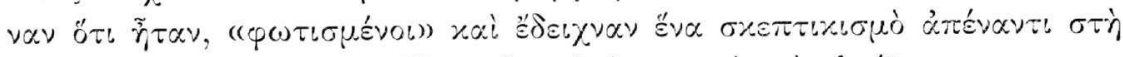

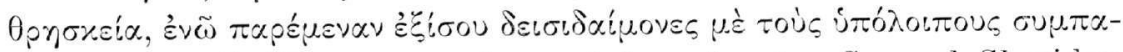

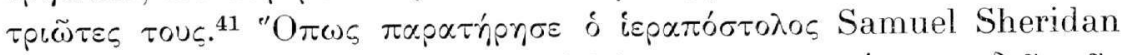

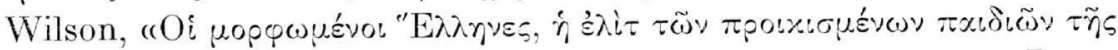

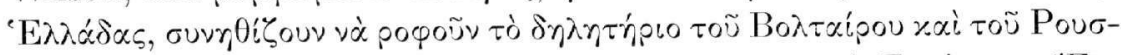

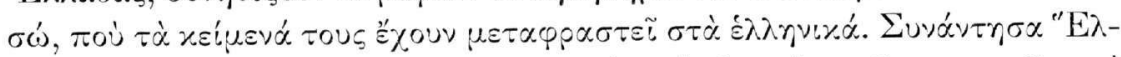

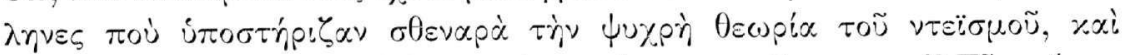

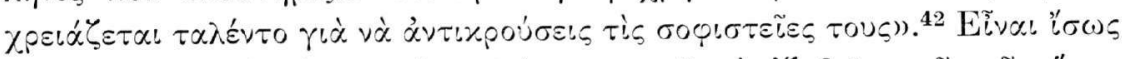

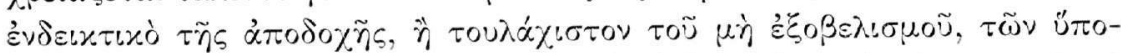

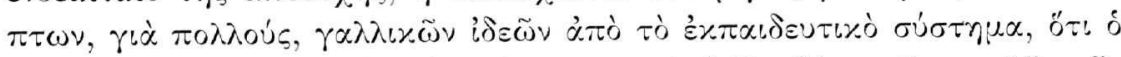

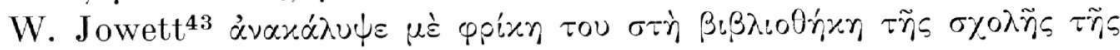

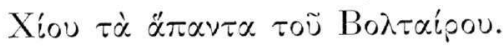

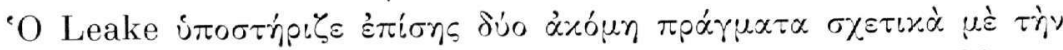

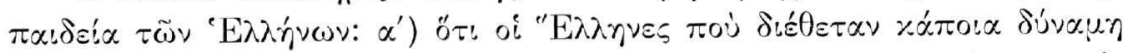

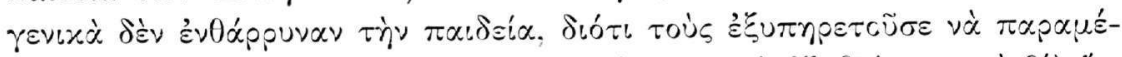

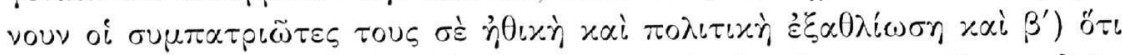

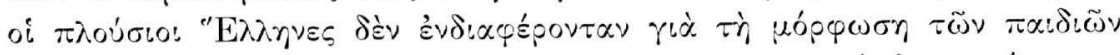

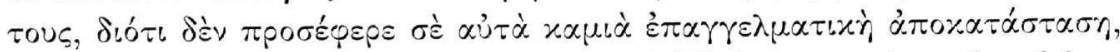

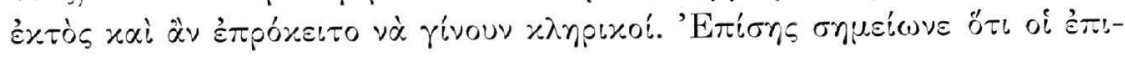

40. "O.л., б. 173, 227-231.

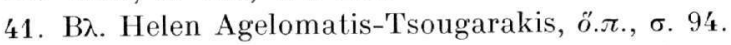

42. A Narrative of the Greek Mission: or Sixteen Years in Malta and Greece ..., London 1839, б. 206-7.

43. Christian Researches in the Mediterranean from MDCCCXV to MDCCCXX, London 1822, б. 60 . 


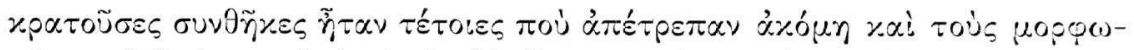

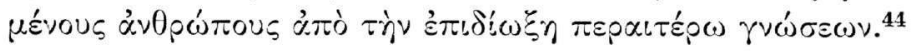

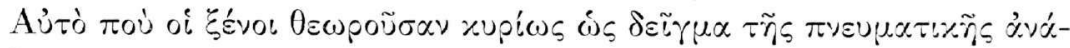

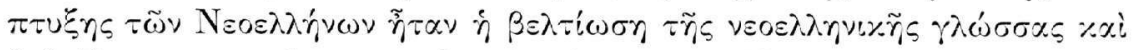

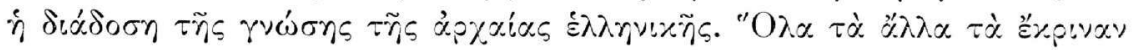

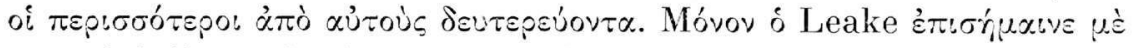

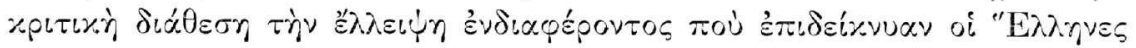

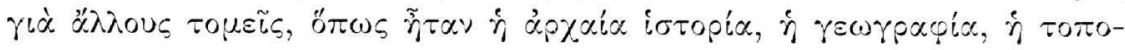

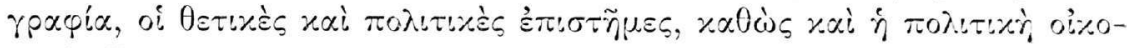
vouía. ${ }^{45}$

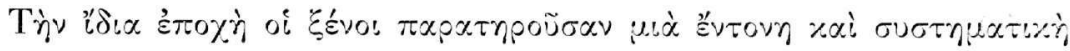

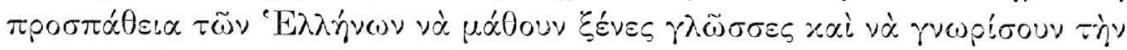

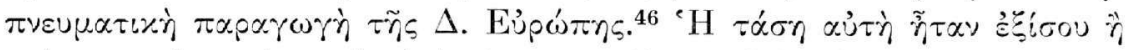

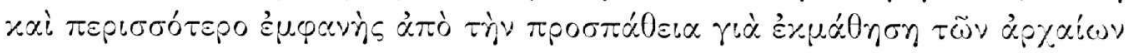

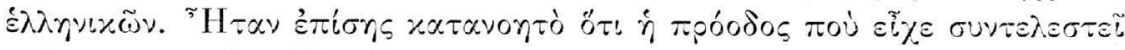

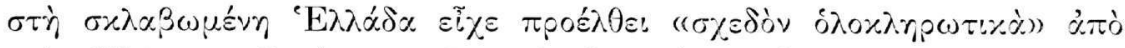

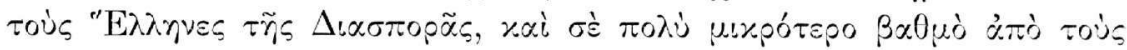

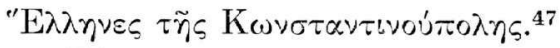

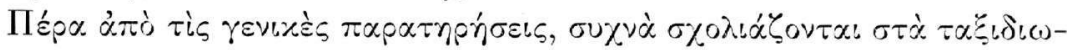

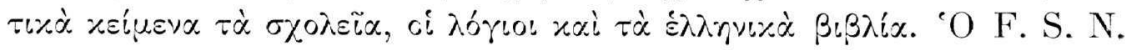

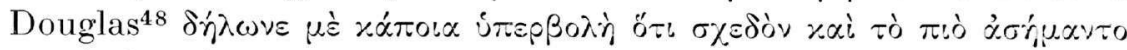

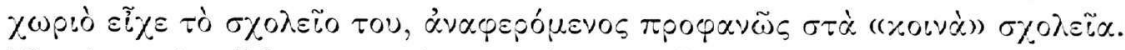

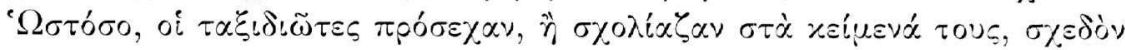

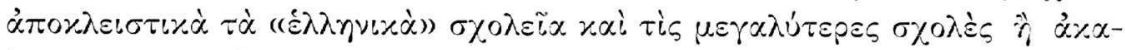

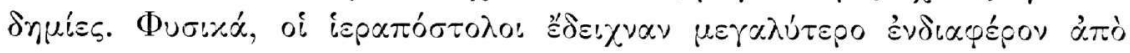

44. "O.л., б. 67. William Martin Leake, Travels in Northern Greece,

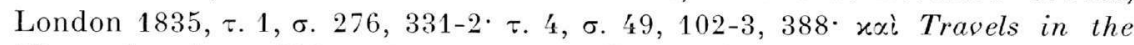

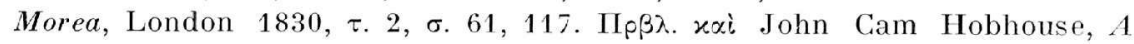
Journey through Albania and Other Prosinces of Turkey in Europe and Asia

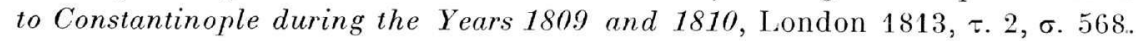

45. Researches in Greece, $\sigma .235$.

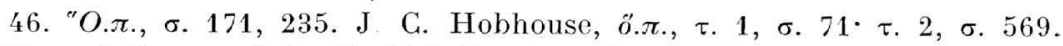
W. Eton, A Survey of the Turkish Empire..., London ${ }^{4} 1809$, б. 329. C. N. Sonini, Voyage en Grèce et en Turquie, fait par l'ordre de Louis XVI, et avec

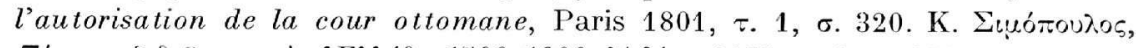

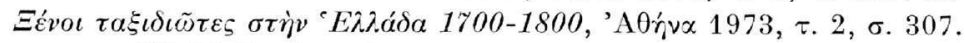

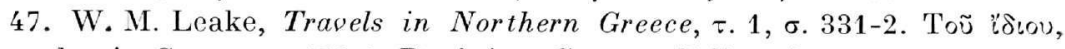

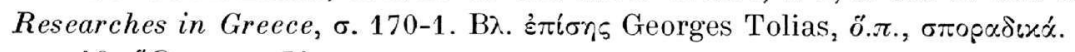

48. "O.л., $\sigma .74$. 


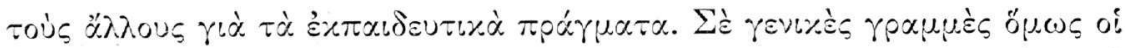

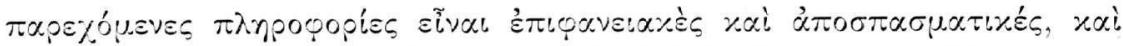

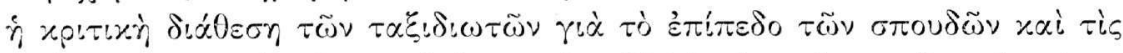

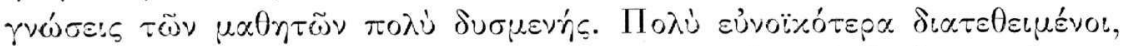

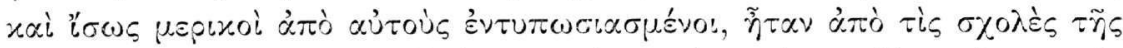

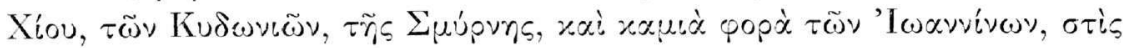

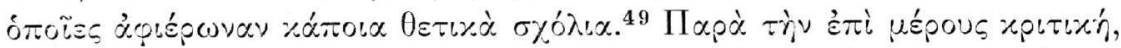

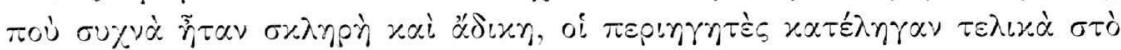

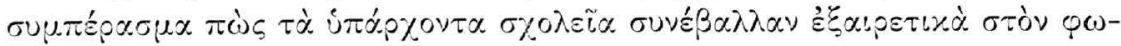

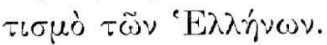

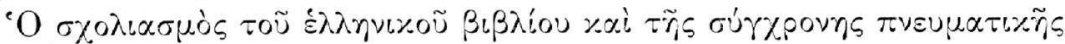

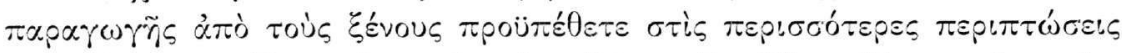

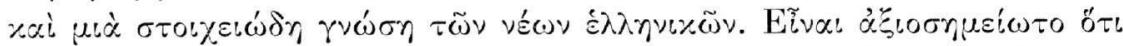
ג.p

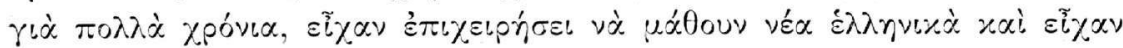

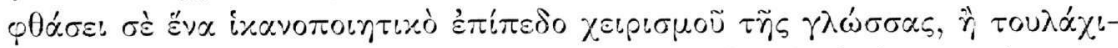

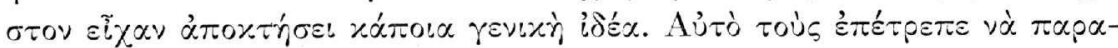

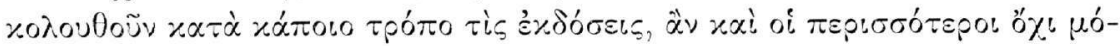

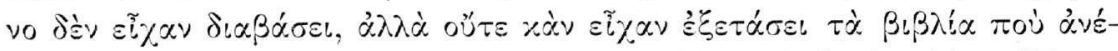

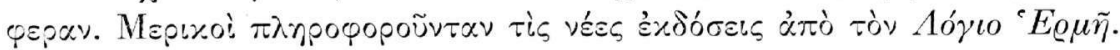

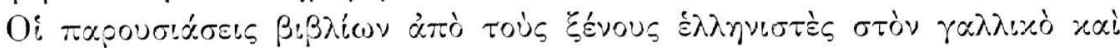

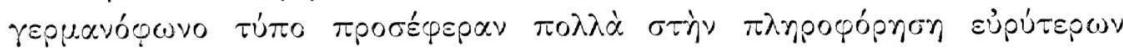

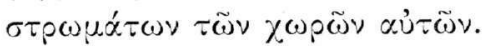

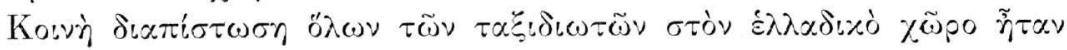

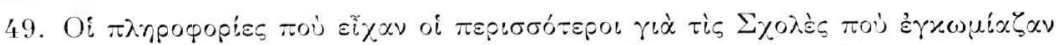

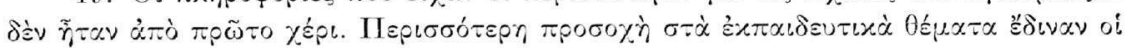

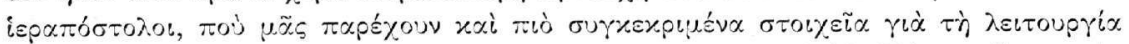

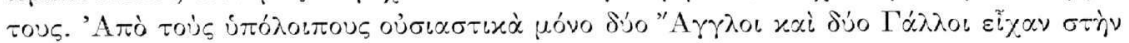

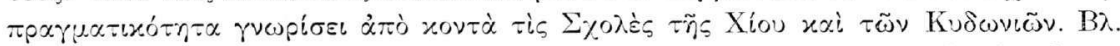

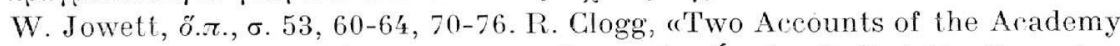
of Ayavalik (Kydonies) in 1818-1819), Resue des Études du Sud-Est Européen,

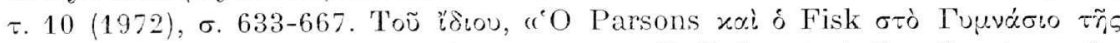

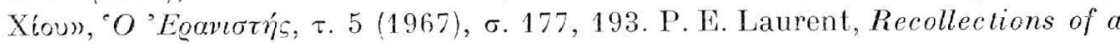
Classical Tour through Various Parts of Greece, Turkey and Italy, Made in the Years 1818 and 1819, London 1821, б. 28. J. Fuller, Narrative of a Tour through Some Parts of the Turkish Empire, London 1830, б. 516-7. A. F. Didot, Notes d'un voyage fait dans le Levant en 1816 et 1817, Paris 1826, $\sigma$. 381-5. M. L. J. comte de Marcellus, Sousenirs de l'Orient, Paris 1839, $\tau .1, \sigma$. 188-9. 


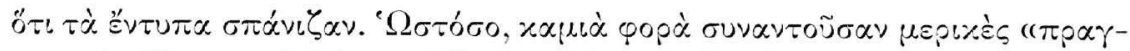

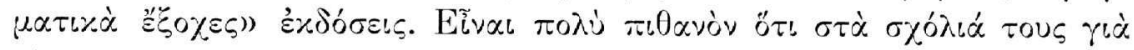

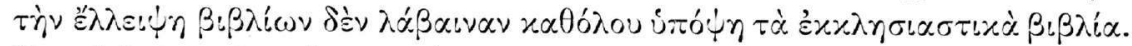

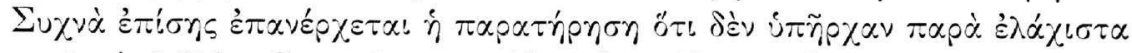

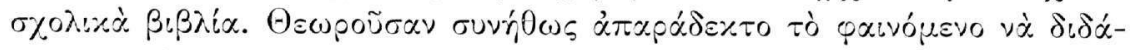

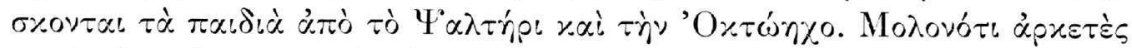

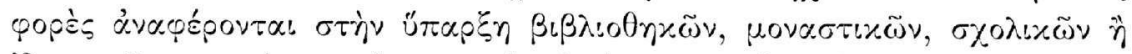

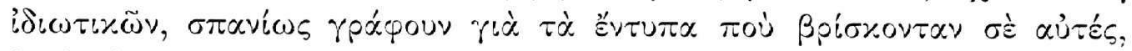

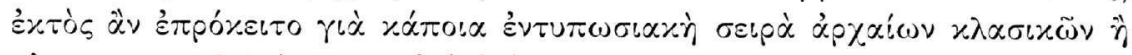

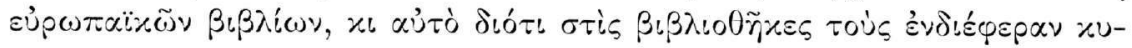

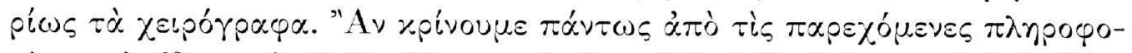

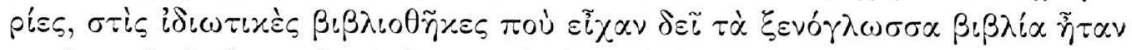

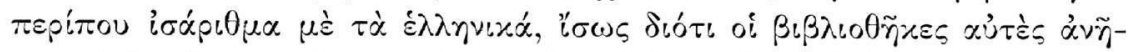

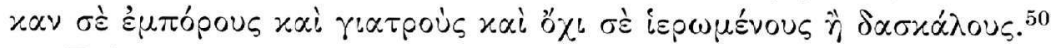

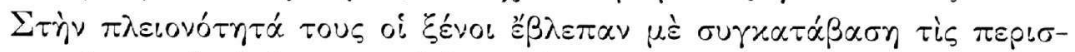

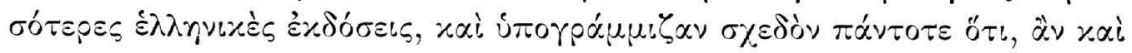

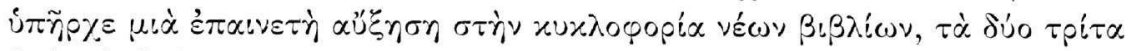

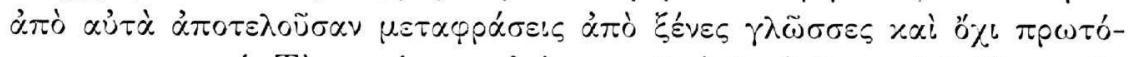

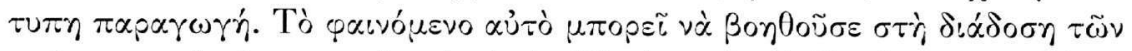

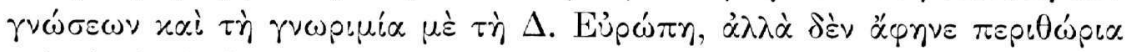

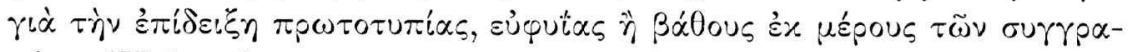

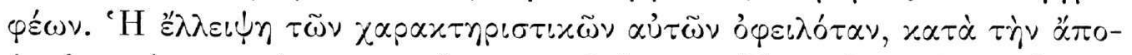

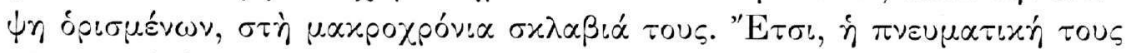

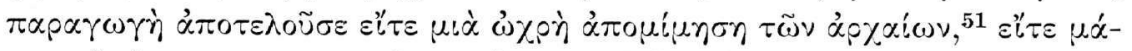

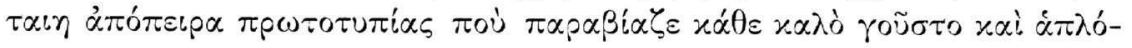

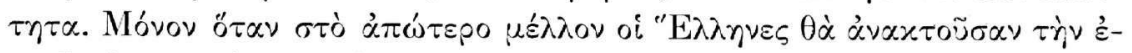

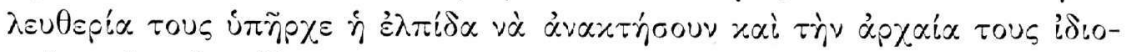

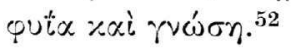

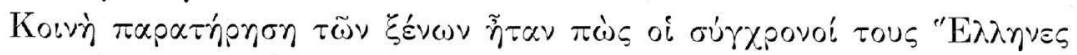

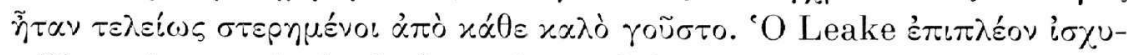

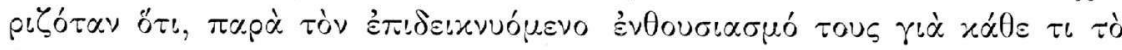

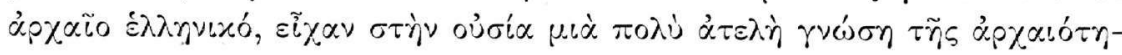

50. Helen Angelomatis-Tsougarakis, ö.л., б. 136-9.

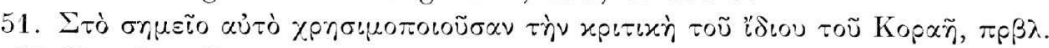
F. S. N. Douglas, ö.л., б. 78-79.

52. W. M. Leake, Researches in Greece, $\sigma .231,233$. H. Holland, Travels in the Ionian Isles, Albania, Thessaly, Macedonia, etc., during the Years 1812

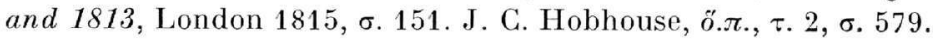




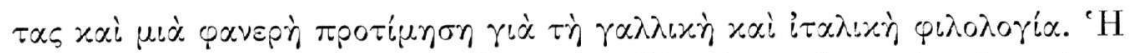

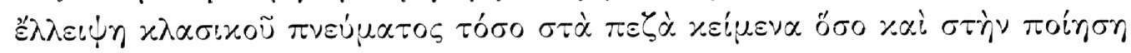

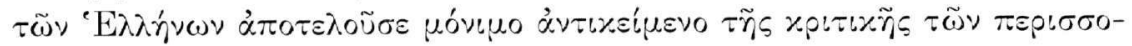
$\tau \varepsilon \dot{\rho} \rho \omega \nu \pi \varepsilon p: \eta \gamma \eta \tau \tilde{\omega} v .{ }^{53}$

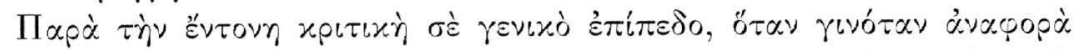

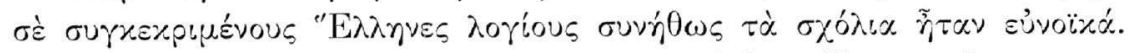

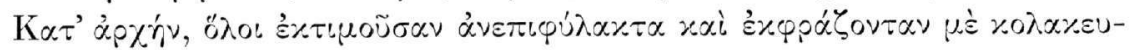

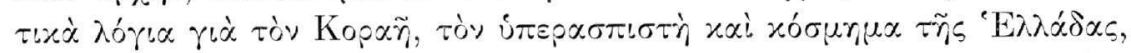

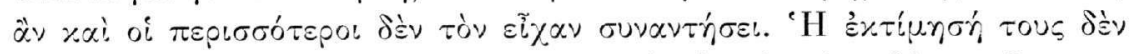

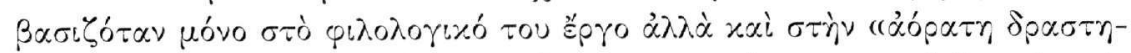

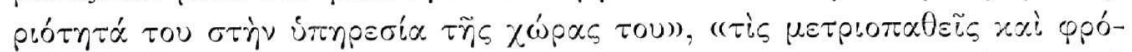

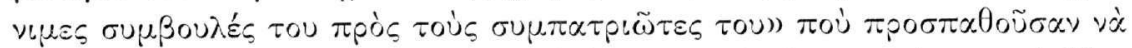

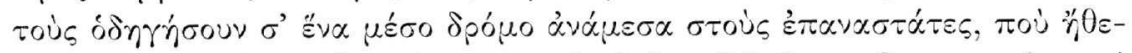

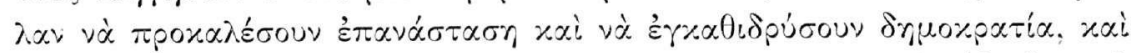

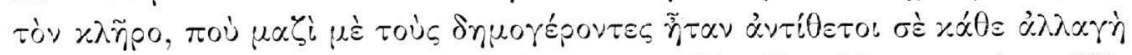

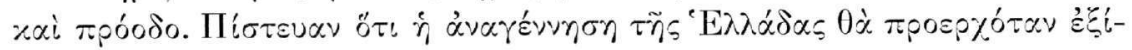

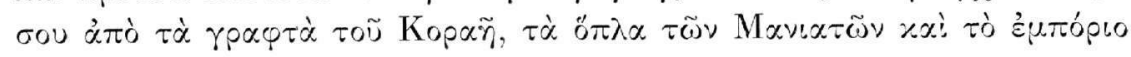

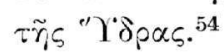

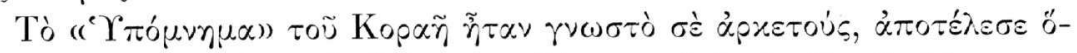

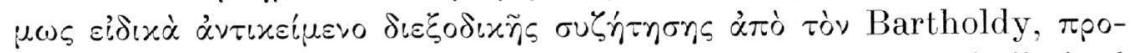

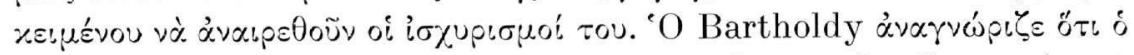
Kopañs cest sans contredit le plus savant de tous les Grecs vivant

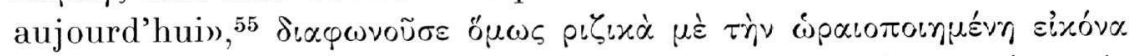

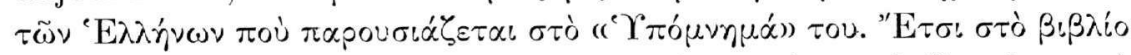

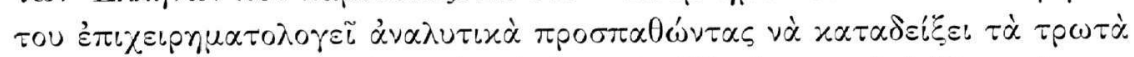

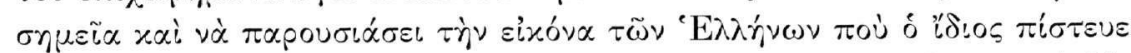

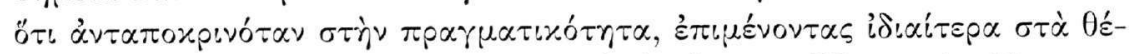

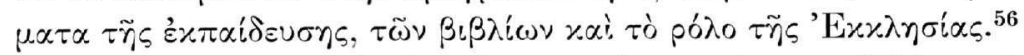

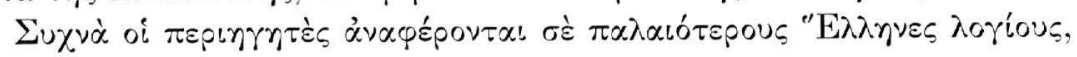

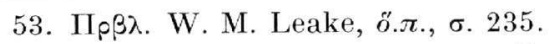

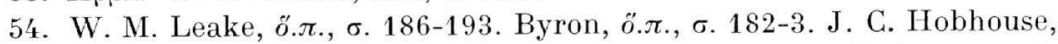

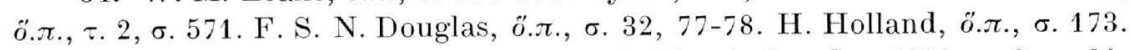

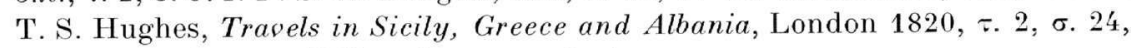

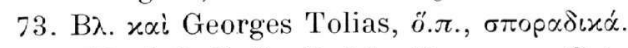

55. J. L. S. Bartholdy, Voyage en Grèce fait dans les années 1803 et $1804 \ldots$

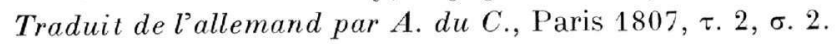

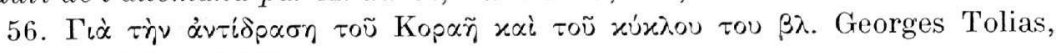

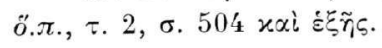




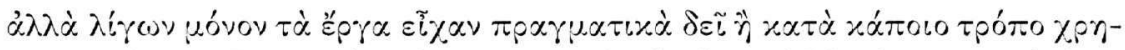

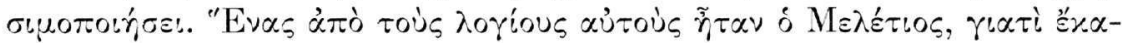

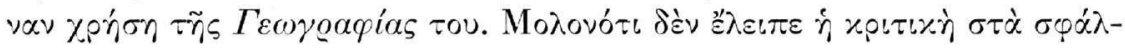

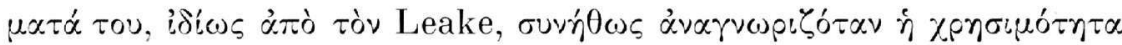

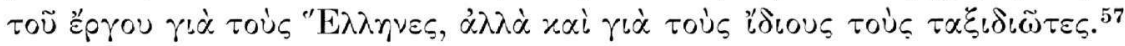

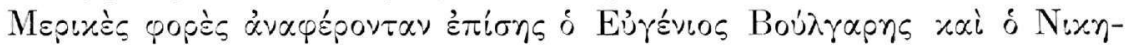

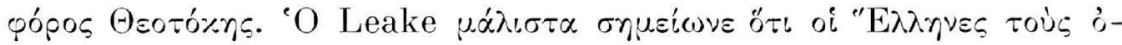

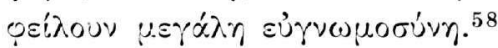

'A

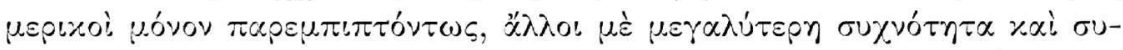

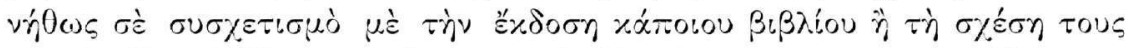

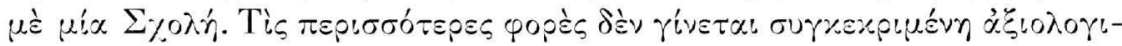

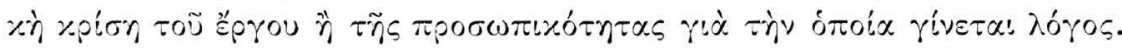

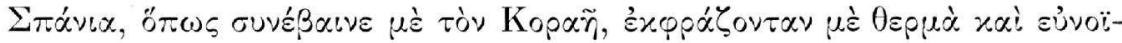

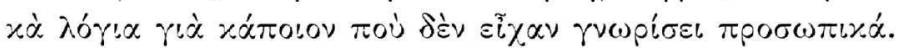

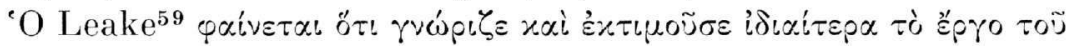

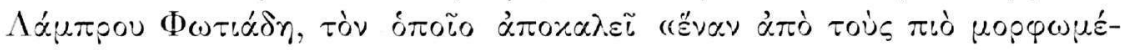

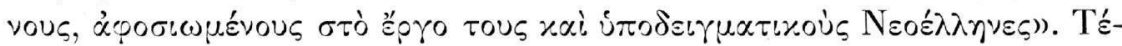

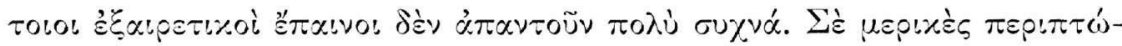

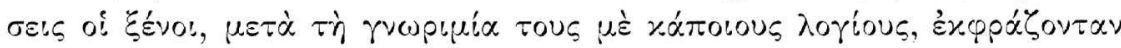

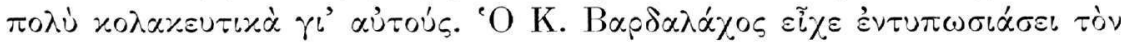

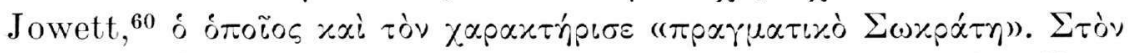

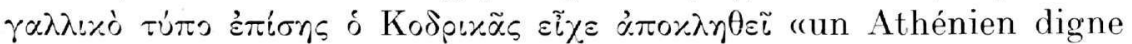
du siècle de Périclès). ${ }^{61}$

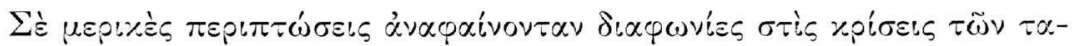

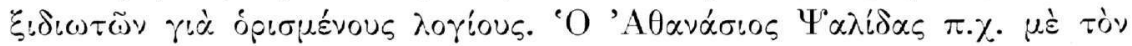

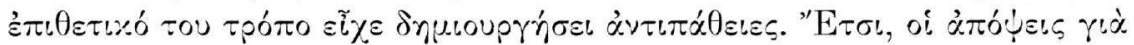

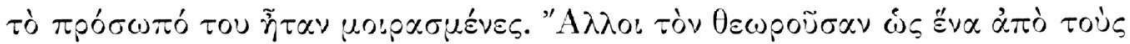

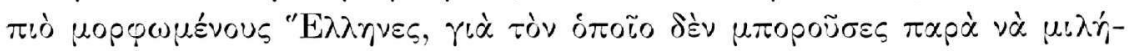

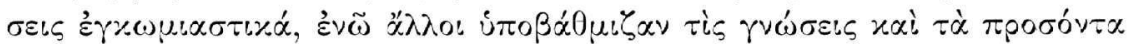

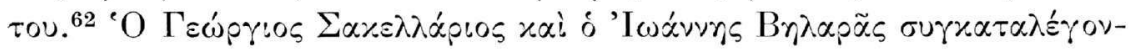

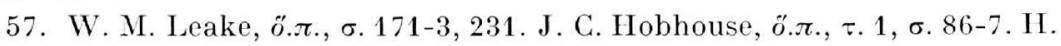

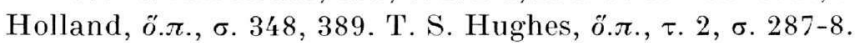

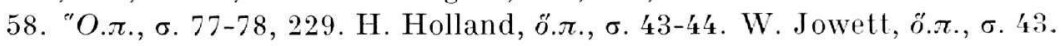

59. "O.л., б. 91.

60. W. Jowett, ö. $\pi .$, б. 69-70, 413.

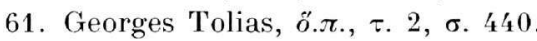

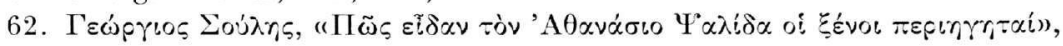




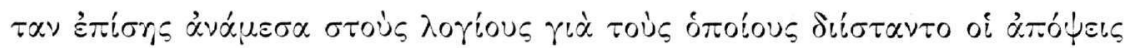

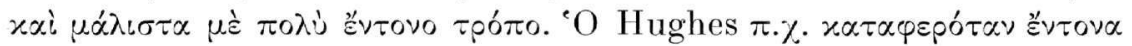

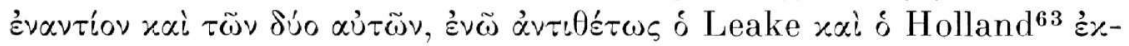

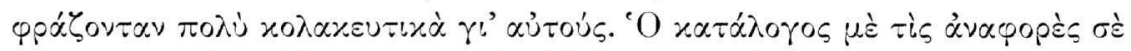
"E

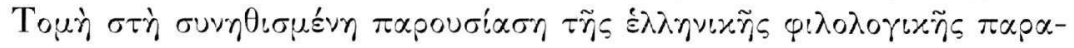

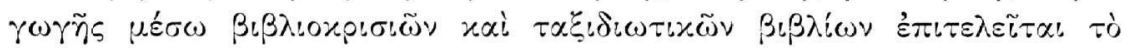

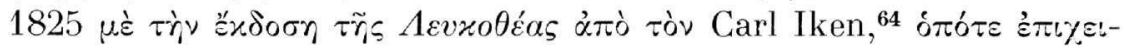

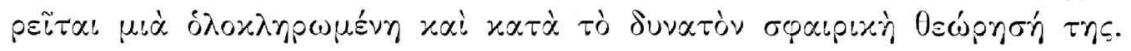

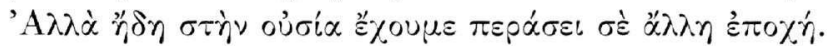

'A

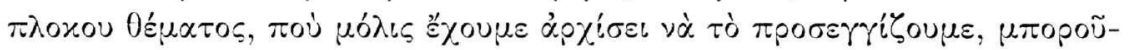

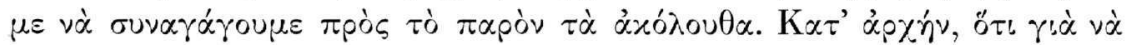

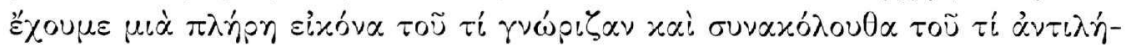

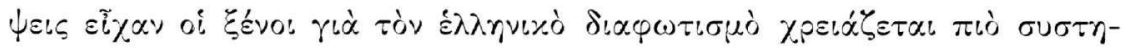

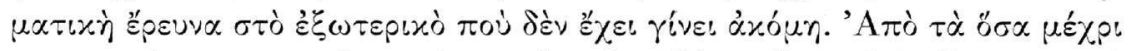

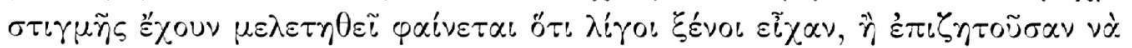

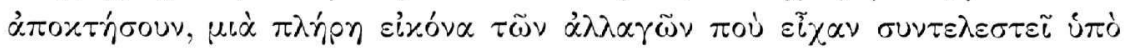

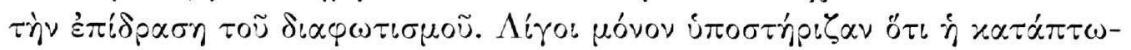

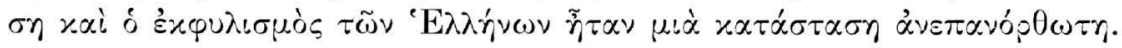

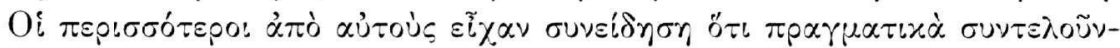

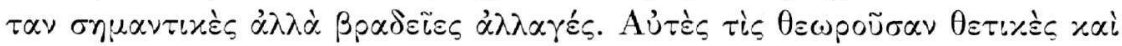

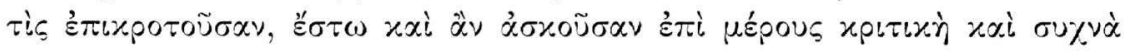

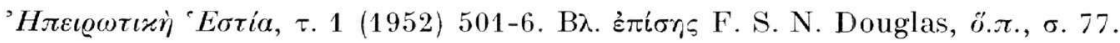
C. R. Cockerell, Travels in Southern Europe and the Levant, 1810-1817. The Journal of C.R. Cockerell edited by his son Samuel Pepys Cockerell, London 1903, б. 237. William Turner, Journal of a Tour in the Levant, Lon-

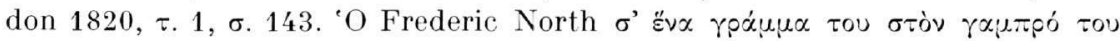

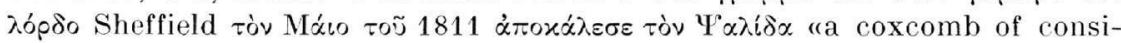
derable erudition', British Library, Add. Ms 61982, ९. $41 \alpha$.

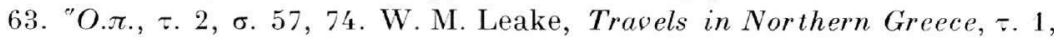

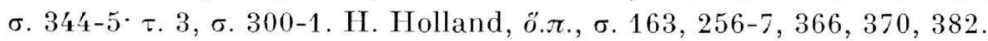

64. Leukothea, Sammlung von Briefen eines geborenen Griechen über Staatswesen, Literatur und Dichtkunst des neueren Griechenlands, I-II, Leip-

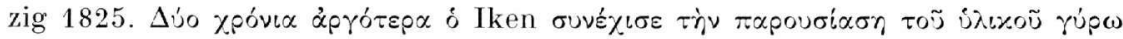

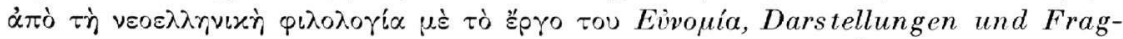
mente neugriechischer Poesie und Prosa. In Originalen und Übersetzungen. Aus englischen und französischen Werken, und aus dem Munde geborener Griechen entlehnt. Mit Beiträgen von verschiedenen Verfassern..., Grimma 1827.
} 


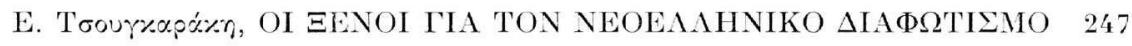

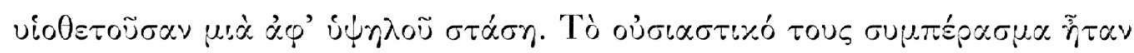

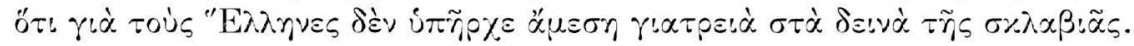

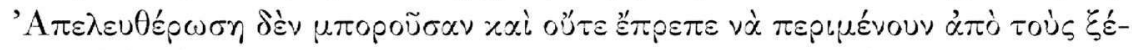

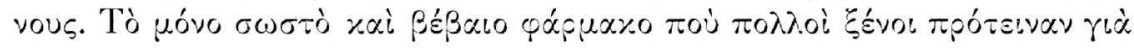

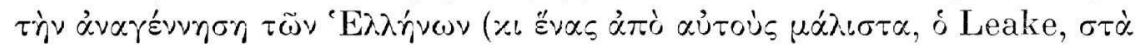

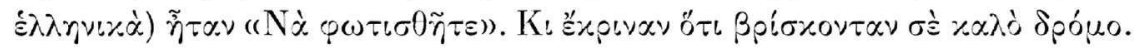

EAENH AГTEAOMATH-T 